\title{
Targeted inhibition of STATs and IRFs as a potential treatment strategy in cardiovascular disease
}

\author{
Malgorzata Szelag ${ }^{1}$, Anna Piaszyk-Borychowska ${ }^{1}$, Martyna Plens-Galaska ${ }^{1}$, Joanna \\ Wesoly ${ }^{2}$ and Hans A.R. Bluyssen ${ }^{1}$ \\ ${ }^{1}$ Department of Human Molecular Genetics, Institute of Molecular Biology and Biotechnology, Faculty of Biology, Adam \\ Mickiewicz University, Poznan, Poland \\ ${ }^{2}$ Laboratory of High Throughput Technologies, Institute of Molecular Biology and Biotechnology, Faculty of Biology, Adam \\ Mickiewicz University, Poznan, Poland \\ Correspondence to: Hans A.R. Bluyssen, email: h.bluyss@amu.edu.pl
}

Keywords: STAT, IRF, vascular inflammation, in silico modeling, therapeutic strategy

Received: December 08, $2015 \quad$ Accepted: April 22, 2016

Published: May 05, 2016

\section{ABSTRACT}

Key factors contributing to early stages of atherosclerosis and plaque development include the pro-inflammatory cytokines Interferon (IFN)a, IFNy and Interleukin (IL)-6 and Toll-like receptor 4 (TLR4) stimuli. Together, they trigger activation of Signal Transducer and Activator of Transcription (STAT) and Interferon Regulatory Factor (IRF) families. In particular, STAT1, 2 and 3; IRF1 and 8 have recently been recognized as prominent modulators of inflammation, especially in immune and vascular cells during atherosclerosis. Moreover, inflammation-mediated activation of these STATs and IRFs coordinates a platform for synergistic amplification leading to pro-atherogenic responses.

Searches for STAT3-targeting compounds, exploring the pTyr-SH2 interaction area of STAT3, yielded many small molecules including natural products. Only a few inhibitors for other STATs, but none for IRFs, are described. Promising results for several STAT3 inhibitors in recent clinical trials predicts STAT3-inhibiting strategies may find their way to the clinic. However, many of these inhibitors do not seem STATspecific, display toxicity and are not very potent. This illustrates the need for better models, and screening and validation tools for novel STAT and IRF inhibitors.

This review presents a summary of these findings. It postulates STAT1, STAT2 and STAT3 and IRF1 and IRF8 as interesting therapeutic targets and targeted inhibition could be a potential treatment strategy in CVDs. In addition, it proposes a pipeline approach that combines comparative in silico docking of STAT-SH2 and IRFDBD models with in vitro STAT and IRF activation inhibition validation, as a novel tool to screen multi-million compound libraries and identify specific inhibitors for STATs and IRFs.

\section{ATHEROSCLEROSIS AND INFLAMMATION}

Atherosclerosis is a chronic degenerative disease of the arteries that represents the root cause of the majority of cardiovascular diseases (CVDs) - a group of disorders of the heart and blood vessels: coronary heart disease, cerebrovascular disease, peripheral arterial disease, renal artery stenosis, hypertensive heart disease and their complications, including conditions such as stroke and myocardial infarction (MI). Atherosclerosis remains the leading cause of morbidity and mortality in the western world [1] despite significant progress in the understanding of the pathogenesis and the treatment options. This means that the search for new therapeutic agents and/or therapeutic strategies is necessary.

Atherosclerosis is a progressive disease of large and medium-sized muscular arteries and is characterized by vascular inflammation followed by the buildup of lipids, cholesterol, calcium, and cellular debris within the intima of the vessel wall. Accumulation of these components contributes to plaque formation, vascular remodeling, 
acute and chronic luminal obstruction, abnormalities of blood flow and diminished oxygen supply to target organs [2]. Atherosclerosis can be initiated by several triggers, resulting in endothelial dysfunction, mainly accumulation of oxidized low density lipoproteins (Ox-LDLs) in the intima or contact with microbes and some endogenous molecules which are released by damaged tissue elsewhere in the organism. Sensing receptors that recognize danger signals include Toll-like receptors (TLRs). As part of the innate immune system, endothelial cells (ECs) respond to these triggers by producing cell surface adhesion molecules, chemokines and inflammatory cytokines. These characteristics of ECs dysfunction form an initial step in atherosclerosis development [3]. Subsequent recruitment and translocation of blood borne monocytes and naive lymphocytes from the circulation into the intima are followed by monocyte differentiation into macrophages (MCs). Later MCs` scavenger receptors, which expression is increased by cytokines such as tumor necrosis factor- $\alpha(\mathrm{TNF} \alpha)$ and interferon $\gamma(\mathrm{IFN} \gamma)$, recognize highly oxidized LDL particles which are rapidly taken up by $\mathrm{MCs}$, leading to foam-cells formation [4]. Recent findings indicate that also vascular smooth muscle cells (VSMCs) expressing scavenger receptors can significantly contribute to formation of large proportions of total foam-cell population [5]. Subsets of $\mathrm{T}$ helper 1 (Th1) lymphocytes are important producers of proinflammatory cytokines, including type I IFN (consisting of IFN $\alpha$ and IFN $\beta$ subtypes), type II IFN (IFN $\gamma$ ), $\mathrm{TNF} \alpha$ and interleukin 6 (IL-6), all of which promote atherogenesis [6]. Dendritic cells (DCs), which originate from precursors derived via the bloodstream and produce large amounts of type I IFN in response to bacterial and viral infections, have recently been revealed to play important roles in onset and progression of atherosclerosis, as well as plaque destabilization [7, 8]. Finally, VSMCs which undergo de-differentiation, start to proliferate and phagocytize lipid particles becoming foam-cells, what results in vessel occlusion, neointima and advanced atherosclerotic plaque formation. Excessive inflammatory and immune responses, communicated by these different cell types, are driven by inflammatory cytokines and other inflammatory stimuli that promote associated tissue damage and contribute to local inflammation and vascular dysfunction $[9,10]$.

The transcription factor families of Signal Transducer and Activator of Transcription (STAT) and Interferon Regulatory Factor (IRF) proteins consist of highly conserved members that play a crucial role in fundamental cellular processes, including cell growth and differentiation, development, apoptosis, immune responses and inflammation [11, 12]. The abnormal activation of STAT and IRF signaling pathways is implicated in many human diseases, including CVDs, consequently identifying these proteins as highly interesting therapeutic targets $[13,14]$.

\section{STATs AND IRFs: STRUCTURE AND FUNCTION}

STATs facilitate action of cytokines, growth factors and pathogens. In mammals the STAT family consists of seven members: STAT1, 2, 3, 4, 5A, 5B and 6. Structurally they are composed of 6 conserved domains: a helical N-terminal (ND), a 'coiled-coil' four helix bundle (CC), a central Ig-like DNA-binding domain (DBD), a helical linker (LK), a Src-homology 2 (SH2) domain and a C-terminal transactivation domain (TAD), (Figure 1A: structures are shown for human STAT1, 2 and 3). STAT activation is mediated by phosphorylation of a critical tyrosine residue, located between the SH2 domain and the C-terminal transactivation domain (human STATs: STAT1pY ${ }^{701}$, STAT2-pY ${ }^{690}$, STAT3-pY ${ }^{705}$; murine STATs: STAT1pY ${ }^{701}$, STAT2-pY ${ }^{689}$, STAT3-pY ${ }^{705}$ ). It leads to a cascade of signaling events including STAT dimerization through the reciprocal interaction of the monomers between their phosphotyrosines (pTyr) and $\mathrm{SH} 2$ domains. The active dimers induce gene transcription in the nucleus by binding to specific DNA-response elements of target genes. STAT dimers with 2-fold symmetry recognize a palindromic DNA core motif called GAS element (IFN $\gamma$ activation site, TTCN $_{2-4}$ GAA), (Figure 1B).

Binding affinity to GAS elements vary between STATs. For example, the TTC(N) GAA is an optimal variant for STAT1, which prefers binding sites that have an intra-site spacer of three bases CCG. On the other hand, STAT3, 4, and 5A/B prefer to bind at sites with spacers from 2 to 4 bases, of which the majority of highequilibrium binding intensity interactions occur at sites with a 3 base spacer $[15,16]$. Finally, STAT6 binds sites in which two halves of the palindromic core are separated by four nucleotides, creating TTC(N) GAA motif. A GAS element in the mouse Ly6E gene [17] binds preferentially STAT1 over STAT3 homodimers or STAT1-STAT3 heterodimers [18]. A GAS variant named Sis-inducible element (SIE) in the c-fos promoter binds to STAT1 as well as STAT3 $[19,20]$. Also, the SIE m67 binding site from the human c-fos promoter [21] binds STAT1 and STAT3 [18], but not STAT4 or STAT5A/B [22].

IRF proteins are modulators of the defense mechanisms in the human body against pathogens including innate and adaptive immunity. IRFs are primarily related to the innate response of the immune system that is dependent on pattern-recognition receptors (PRRs), including TLRs. They increase the transcription of type I IFN and IFN-inducible genes (ISGs) during immune system development, homeostasis and activation by IFNs and microbes. Mammalian IRFs comprise a family of nine homologous proteins (IRF1-9) with a multi-domain structure. An additional IRF, IRF10, has been identified in chickens [23]. The N-terminal half of the IRF protein provides the DBD and is characterized by the presence of five tryptophan residues spaced ten 
to eighteen amino acids apart in a 'tryptophan cluster' (Figure 1C: structures are shown for IRF1 and IRF8) [24]. The IRF family share sequence and structural homology in their DNA binding regions. Each IRF-DBD has the fold of a 'helix-turn-helix' and recognizes a similar DNA motifIFN regulatory element (IRE, NAANNGAAA) [25], that is present in the regulatory regions of IFNs and ISGs or binds to its tandem-repeat form called the IFN-stimulated response element (ISRE, A/GNGAAANNGAAACT) [26]. The C-terminal halves of all IRF family members contain either an IRF association domain 1 (IAD1) or an IAD2, with which they bind to IRF family members, other transcription factors, or self-associate, which is crucial during DNA binding (Figure 1D). These interactions allow IRFs to modulate their activity and bind a variety of genes. The IAD1 is approximately 177 amino acids in length, and is conserved in all IRFs except IRF1 and IRF2 [25, 27, 28]. IAD2 is present only in IRF1 and
IRF2 [28]. Finally, the C-terminal region of a selection of IRFs contains a regulation site that is dependent on phosphorylation. For IRF3 and IRF7 phosphorylation of this region upon viral infection mediates a conformational change that enhances homo- or heterodimerization, nuclear localization and transactivation $[28,29]$. Likewise, IRF1 phosphorylation at several sites in the C-terminal half increases DNA binding and transcriptional activity with casein kinase II (CKII) as one of the responsible kinases $[27,30]$. Phosphorylation of IRF8 is mediated by CSN (COP9/signalosome) complex at an non-conserved serine residue within its IAD, $\operatorname{Ser}^{260}$. This phosphorylation event is essential for efficient association with IRF1 [31]. Moreover IRF2, 4, 5, 6, but not 9 also undergo phosphorylation resulting in increasing DNA binding, protein degradation and/or functional activity [32-35].

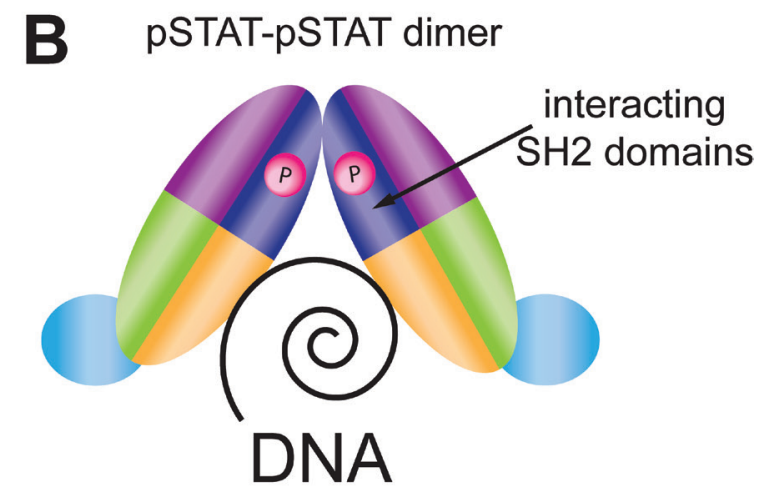

D

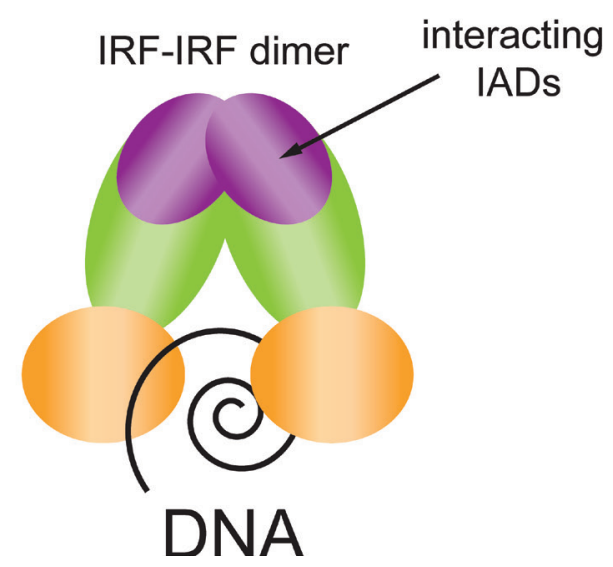

Figure 1: Human STAT and IRF proteins general structure and DNA binding mechanism. A. Functional domains of human STAT proteins (hSTAT1, hSTAT2 and hSTAT3 respectively). ND: N-terminal domain; CC: coiled-coil domain; DBD: DNA-binding domain; LK: linker domain; SH2: Src-homology 2 domain; Y-P: phosphorylated tyrosine; TA: transcriptional activation domain. B. Dimer of phosphorylated humanSTAT binding to DNA. Colors of domains are according to those assigned under A. Dimerization involves interaction between the phosphorylated tyrosine of one hSTAT molecule and the SH2 domain of the dimer partner in a parallel orientation that is a prerequisite for DNA binding. C. Functional domains of human IRF proteins (hIRF1 and hIRF8 respectively). DBD: DNAbinding domain; AD: activation domain; IAD: IRF association domain type 1 (IAD1) or type 2 (IAD2); P: phosphorylation site; 5W: five tryptophan repeats - 'tryptophan cluster'. D. Dimer of human IRF binding to DNA. Colors of domains are according to those assigned under C. Dimerization involves interaction between the IAD of one hIRF molecule and the corresponding IAD of the dimer partner in a parallel orientation that is a prerequisite for DNA binding. 
Table 1: The role of STATs and IRFs in CVD

\begin{tabular}{|l|l|l|}
\hline $\begin{array}{l}\text { Transcription } \\
\text { factor }\end{array}$ & Contribution to CVD development & References \\
\hline STAT1 & $\begin{array}{l}\text { Foam-cell formation, atherosclerotic lesion development, MC apoptosis, } \\
\text { VSMCs de-differentiation and proliferation, neointimal hyperplasia, } \\
\text { elevated expression of chemokines, promotion of oxidative stress and } \\
\text { tissue injury. }\end{array}$ & {$[74,87-91]$} \\
\hline STAT2 & Regulation of type I IFN signaling and gene expression. & {$[92]$} \\
\hline STAT3 & $\begin{array}{l}\text { VSMCs de-differentiation, lesion formation, recruitment of of } \\
\text { inflammatory cells to the vessel wall. }\end{array}$ & {$[93,94]$} \\
\hline IRF1 & $\begin{array}{l}\text { Protection against neointima formation, iNOS activation in response to } \\
\text { stress conditions, increased ventricular dilation and fibrosis, acceleration } \\
\text { of vascular remodeling, exacerbation of ischaemic stroke. }\end{array}$ & {$[97-100]$} \\
\hline IRF8 & $\begin{array}{l}\text { Cells proliferation, neointima and lesion formation, association of } \\
\text { IRF8 gene polymorphism with coronary heart disease in SLE, elevated } \\
\text { expression in response to mechanical injury of the artery, VSMC } \\
\text { phenotypic switching, induction of M1 phenotype in MC, negative } \\
\text { regulator of pathological cardiac hypertrophy. }\end{array}$ & {$[100-102$,} \\
\hline
\end{tabular}

\section{TLRs, IFNs AND IL-6 IN ATHEROSCLEROSIS}

Recent evidence from a variety of experimental approaches has indicated that TLRs play key roles in the development of atherosclerosis. In particular TLR4 is expressed in both human and mouse atherosclerotic lesions [36]. Also, patients with acute coronary syndromes or coronary arteriosclerotic lesions display increased TLR4 expression on circulating monocytes as compared with control patients [37]. ApoE $\mathrm{E}^{-/}$mice deficient in TLR4 have reduced atherosclerosis, which establishes that TLR activated pathways contribute to disease development [38].

TLR4 and its agonists are associated with onset and progression of atherosclerosis. Pathological states like septic shock may promote atherosclerosis, however one of the other proposed mechanisms is endotoxemia due to dietary habits. Cani et al. reported that mice fed on high fat diet had increased plasma concentration of one of the pathogen-associated molecular pattern molecules (PAMPs) - lipopolysaccharides (LPS) [39]. In other studies, Amar et al. revealed a link between energy intake and endotoxin concentration in humans and Szeto et al. suggested that degree of circulating endotoxemia might be related to the severity of systemic inflammation and features of atherosclerosis [40, 41], what may support the hypothesis that increased fat intake, leads to inflammatory responses induced with LPS absorption from the intestinal microbiota [42]. Moreover, an effect of LPS on plaque progression has been recently observed [43]. ApoE $\mathrm{E}^{-/-}$mice treated with Rhodobacter sphaeroides lipopolysaccharide (TLR4 antagonist) had reduced atherosclerotic lesions. In addition to PAMPs such as LPS or Chlamydia pneumoniae, there are also damage- associated molecular pattern molecules (DAMPs) with an established link to atherosclerosis [44]. Kanellakis et al. showed that high-mobility group box 1 protein (HMGB1, also known as amphoterin) is implicated in the progression of atherosclerotic plaque development. Treatment with anti-HMGB1 antibodies reduced DCs, CD4+ T-cells, macrophages infiltration as well as expression of proinflammatory cytokines [45]. Together, TLR4-activated signaling has been implicated in the activation of vascular cells during atherogenesis, and in promoting the dysregulation of MCs cholesterol metabolism that is a prerequisite for the formation of foam-cells and lesion progression in vivo [46, 47].

Type I IFNs are produced by various cell types and induce antiviral responses and immune-modulating activities $[48,49]$. Type II IFN is derived from T cells and is vital for both innate and adaptive immunity by activating MCs, natural killer cells, B cells and vascular ECs and SMCs [50]. Recent data support a causal relationship between type I IFNs signaling and atherosclerosis. Ldlr ${ }^{-/}$ mice (deficient in the LDL receptor gene) fed a western diet have increased atherosclerosis with low dose IFN $\alpha$ treatment [51]. Likewise, IFN $\beta$ administration promoted atherosclerosis in both a collar-induced model in $\mathrm{ApoE}^{-1-}$ mice, as well as in western diet fed Ldlr ${ }^{-/}$mice [52]. Upregulation of IFN $\alpha$ signaling is also associated with atherosclerotic lesions. Specifically, DCs have been identified in human atherosclerotic lesions and have been associated with rupture $[52,53]$.

IFN $\gamma$ is necessary and sufficient to cause vascular remodeling. The serological neutralization or genetic absence of IFN $\gamma$ markedly reduces the extent of atherosclerosis. ApoE ${ }^{-/}$mice fed a western diet have increased atherosclerosis with low dose IFN $\gamma$ treatment 


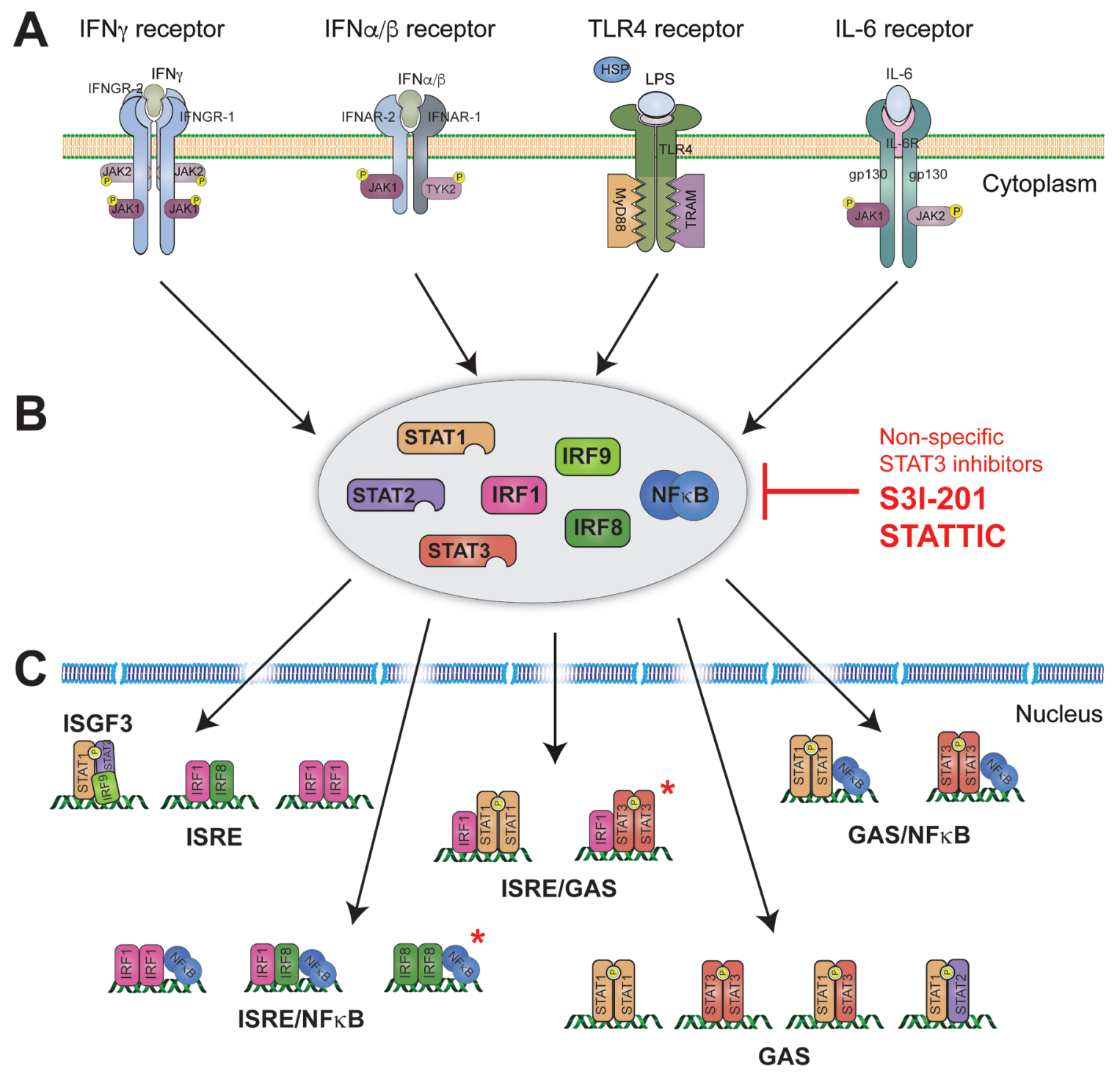

\begin{tabular}{|ll|}
\hline Synergistic amplification of genes involved in: \\
- response to stress & - inflammatory response \\
- defense response & - response to other organism \\
- immune response & - response to wounding \\
\hline
\end{tabular}

Figure 2: Physiological basis of human STAT and IRF signaling of pro-inflammatory triggers. A. Signaling pathways important in CVDs progression involve activation of 4 receptors: IFN $\gamma$ receptor composed of IFNGR1/IFNGR2 subunits associated with Janus kinases JAK1/JAK2 respectively; IFN $\alpha / \beta$ receptor composed of IFNAR1/IFNAR2 subunits associated with JAK1/TYK2 kinases respectively; TLR4 receptor which consists of TIR domains associated with adapter molecules (MyD88 and TRAM) and IL-6 receptor built of two glycoproteins (gp130) and IL-6 receptor subunit (IL-6R), associated with JAK1 and JAK2 kinases. Abbreviations: gp130: glycoprotein 130; HSP: heat shock protein; IFN: interferon; IFNAR: interferon alpha/beta receptor; IFNGR: interferon gamma receptor; IL-6: interleukin 6; IL-6R: interleukin 6 receptor; JAK: Janus kinase; LPS: lipopolysaccharide; MyD88: myeloid differentiation primary response 88; TLR: toll-like receptor; TRAM: TRIF-related adaptor molecule; TYK: tyrosine kinase. B. NF-kB, STAT1, STAT2, STAT3, IRF1 and IRF8 are key players in cell signaling and transcription in response to IFNs, IL-6 and TLR4 and in various ways. Non-specific STAT3 inhibitors, i. e. S3I-201 and STATTIC, could be used to inhibit cooperative involvement of NF-kB, STATs and IRFs. Abbreviations: IRF: interferon regulatory factor; NF-kB: nuclear factor kappa B; STAT: signal transducer and activator of transcription. C. Through binding to DNA as homodimers (e. g. STAT1, STAT3, IRF1: on GAS or ISRE), heterodimers (STAT1-STAT2, STAT1-STAT3, IRF1-IRF8: on GAS or ISRE), macromolecular complexes (e. g. ISGF3: on ISRE) or assemblies with other proteins (STAT-NF-kB, IRF-NF-kB, IRFSTAT: on ISRE/NF-kB, GAS/NF-kB or ISRE/GAS) STATs and IRFs are responsible for synergistic amplification of gene expression that lead to pro-atherogenic responses. *Hypothetical STAT and IRF protein assemblies that might be also present in synergistic amplification of genes in CVDs. Abbreviations:GAS: interferon-gamma activated sequence, ISRE: interferon stimulated response element. 
(Bluyssen and Poledne 2015, unpublished results). IFN $\gamma$ is expressed at high levels in atherosclerotic lesions thus playing a pro-inflammatory role in the pathogenesis of atherosclerosis and regulating the functions and properties of all cell types present in the vessel wall. In addition, IFN $\gamma$ induces chemokine production, adhesion, apoptosis, and matrix deposition, and has a range of pathophysiological properties that resemble ECs dysfunction and could promote development of atherosclerotic lesions [50, 54, 55].

IL-6, like IFN $\gamma$, has been regarded as a member of the pro-inflammatory cytokines as well, and proposed to contribute to both, atherosclerotic plaque development and plaque destabilization by release of other proinflammatory cytokines, oxidation of lipoproteins by phospholipases, stimulation of acute phase protein (APP) secretion, the release of prothrombotic mediators, and the activation of matrix metalloproteinases [56]. Treatment with recombinant IL-6 in atherosclerosisprone $\mathrm{ApoE}^{-/-}$mice resulted in aggravated atherosclerotic state which was accompanied by increased levels of other pro-inflammatory cytokines and APPs [57]. Plasma concentrations of IL-6 were identified as a risk predictor for MI [58]. Similarly, increased plasma IL-6 is related to endothelial dysfunction and atherosclerosis development [59]. Tocilizumab, a monoclonal antibody binding the IL-6 receptor, has been shown to improve endothelial function and reduce arterial stiffness, what may indicate a strategy that interferes with IL-6 signaling on vascular function and integrity [60].

\section{STATs and IRFs in TLR, IFN and IL-6 signaling}

Type I and type II IFNs and IL-6 induce gene expression by phosphorylating STAT members in a Januskinase (JAK)-dependent manner (Figure 2). IFN $\alpha / \beta$ induced STAT1 and STAT2 heterodimers, combined with IRF9 to form ISGF3, activate expression of ISREcontaining genes (Figure 2). IFN $\alpha / \beta$ and IFN $\gamma$ as well as IL-6 are able to activate the formation of STAT1 or STAT3 homo- and heterodimers, which then promote the expression of a distinct set of GAS-driven genes (Figure 2) [61-63]. In response to type I IFNs signaling also STAT1-STAT2 heterodimers are created, which bind to GAS sequence and induce e. g. IRF1 gene expression [64]. In general, STAT1 and STAT2 are considered proinflammatory, whereas STAT3 has pro- as well as antiinflammatory characteristics. IFNs additionally activate transcription factors of the IRF family. The most important ones are IRF1 and IRF8, particularly by amplifying ISREor GAS-dependent gene expression initiated by STAT1 and or STAT2 (Figure 2) [65]. IRF1 preferentially binds to DNA as a homodimer, whereas IRF8 needs a binding partner, for example IRF1 [27].

TLR ligation results in the rapid activation of signal dependent transcription factors, including members of the nuclear factor- $\kappa \mathrm{B}(\mathrm{NF}-\kappa \mathrm{B})$, IRF (Figure 2) and activator protein 1 (AP1) families $[47,65,66]$. These factors collectively mediate rapid expression of hundreds of genes that amplify the initial inflammatory response, exert antimicrobial activities and initiate the development of acquired immunity. Several of the cytokines that are upregulated in the initial wave of immediate early gene expression function in feed forward transcriptional loops particularly important examples being IFN $\beta$, which induce a secondary wave of STAT1 and STAT2 dependent gene expression, and TNF which sustains NF- $\kappa \mathrm{B}$ signaling. On the other hand, IL-6 activates STAT3. TLRs have also been shown to utilize the IRF family. Specifically, IRF1, $3,5,7$ and 8 were shown to contribute to TLR-activated signaling $[65,67,68]$, being responsible for type I IFN production [69] and with IRF1 and IRF8 participating in cross-talk between inflammatory cytokine and TLR4 signaling (see below) (Figure 2).

The activation of these transcription factors suggests that their relative abundance, which may vary substantially in different cell types, under different conditions is likely to have a major impact on how cells behave in response to IFNs, TLR4-ligands and IL-6.

\section{Cross-talk between inflammatory cytokines and TLR4 signaling}

By sharing the same important transcription factors that have the ability to activate gene expression in different combinations, IFNs, IL-6 as well as TLR4 participate in signaling cross-talk. This can lead to synergistic amplification of common sets of genes through combinatorial actions of transcription factors on ISRE, GAS, ISRE/GAS, ISRE/NF- $\kappa$ B or GAS/NF- $\kappa$ B binding sites (Figure 2). For example, STAT1-stimulated functions of IFN $\alpha / \beta$ and IFN $\gamma$ supply a platform for increased TLR4 signaling activated by LPS and/or the cooperation with different transcription factors, including IRFs and NF- $\kappa B$ (Figure 2). Together, this coordinates the antimicrobial and inflammatory synergism between IFN $\gamma$ and TLRs in immune cells [70-73]. Recently, we characterized the role of STAT1 in the transcriptional response pathways involved in the interaction between IFN $\gamma$ and TLR4 signaling in ECs and VSMCs [74]. Promoter analysis of the genes encoding multiple chemokines, adhesion molecules and antiviral and antibacterial response proteins followed by chromatin immunoprecipitation followed by qPCR (ChIP-qPCR), predicted that cooperation between NF- $\kappa$ B, STAT1 and/or IRFs is involved in the transcriptional regulation of transcriptional responses to IFN $\gamma$ and LPS [74]. A similar cross-talk phenomena exists for IFN $\alpha$ and LPS. For example, optimal transcriptional regulation of CXCL10 [75], vascular cell adhesion molecule 1 (VCAM-1) [76] and CCL19 [77], involves combined occupation of IRF1 and NFKB binding sites 
Table 2: Natural products modulating STAT3 signaling and their clinical indication

\begin{tabular}{|l|l|l|}
\hline Natural product & Clinical trial (phase) & References \\
\hline Capsaicin & $\begin{array}{l}\text { Chronic obstructive pulmonary disease (Phase 0/I/II), psoriasis (Phase } \\
\text { IV), chronic neck pain (Phase II), rhinitis (Phase I/II/IV), pulmonary } \\
\text { hypertension (Phase II), HIV infections (Phase II/III), peripheral } \\
\text { nervous system diseases (Phase II/III), migraine (Phase I), burning } \\
\text { mouth syndrome (Phase 0). }\end{array}$ & {$[129]$} \\
\hline Cryptotanshinone & Polycystic ovary syndrome (phase not provided). & {$[131]$} \\
\hline Curcumin & $\begin{array}{l}\text { Atopic asthma (phase not provided), dermatitis (Phase II/III), type 2 } \\
\text { diabetes (Phase IV), schizophrenia (Phase I/II), Alzheimer`s disease } \\
\text { (Phase I/II), multiple sclerosis (Phase II), rheumatoid arthritis (Phase } \\
\text { 0). }\end{array}$ & {$[173]$} \\
\hline Resveratrol & $\begin{array}{l}\text { Cardiovascular diseases (Phase I/II), type 2 diabetes (Phase I/II/ } \\
\text { III), obesity (Phase II), Alzheimer`s disease (Phase II/III), memory } \\
\text { impairment (phase not provided). }\end{array}$ & {$[132]$} \\
\hline
\end{tabular}

(ISRE/NFאB in Figure 2). Similarly, the IRF8 gene promoter contains a potential STAT1/NF- $\mathrm{SB}$ module (GAS/NFkB in Figure 2), suggesting that the cooperation of these two transcription factors underlies at the basis of IRF8 synergistic expression [78]. Transcriptional regulation of the $\mathrm{Ccl} 5$ and the Nos2 genes in response to IFN $\gamma$ and LPS has uncovered a similar involvement of IRF 1 and NF- $\kappa \mathrm{B}$, as well as a role of IRF8 [78]. This suggests the possible existence of IRF1/IRF8/NFkBstimulated cross-talk between IFN $\gamma$ and LPS in vascular cells $[74,78]$. Also, the IRF1 promoter contains sequences that are recognized by both STAT1 and NF- $\kappa$ B [79]. Cooperative action of binding sites for STAT1 and IRF1 in response to IFNs has been shown to manage expression of the indoleamine 2,3-dioxygenase 1 (IDO1) gene [80], which is involved in sustaining chronic inflammation. The same holds through for Tap1 and Lmp2 genes, which were shown to possess combined ISRE and GAS elements in their promoters $[80,81]$.

STAT2 (as a component of ISGF3) is activated by type I IFN or LPS (indirectly by IFN $\beta$ released in response to LPS binding to the TLR4 receptor). Thus, like STAT1, STAT2 is involved in complexed interactions between multiple signaling pathways, encompassing ISREcontaining gene expression activation by type I IFN and LPS in STAT1-dependent manner (Figure 2).

STAT3 and NF- $\mathrm{KB}$ are known as core transcription factors constitutively activated in many human tumors, regulating expression of large number of target genes playing important roles in immunity and inflammation [82] (Figure 2). Indeed, a functional cooperation was reported between these two transcription factors, which influences regulation of genes such as chemokines (CCL5), interleukins (IL-1 $\beta$, IL-6, IL-8, IL-17, IL-21, IL22, IL-27), matrix metallopeptidases (MMP2, MMP9), adhesion molecules (ICAM-1) and nitric oxide synthases (iNOS) [83-85]. So far, STAT3/IRF1-combined DNAbinding interactions haves not been described, but it is tempting to speculate that they exist in regulation of expression of selective inflammatory genes (see Figure 2). In summary, we postulate that inflammation-induced activation of NF- $\mathrm{B}$, STAT1, STAT2 and STAT3 and IRF1 and IRF8 coordinates a platform for synergistic amplification through combinatorial interactions of multiple chemokines, adhesion molecules and antiviral and antibacterial response proteins. They are involved in stress response, cell defense, immunity and inflammation as well as response to the other organism or wounding (Figure 2). This is in agreement with our recent data mining studies of atherosclerotic plaque transcriptomes. Indeed, detailed promoter analysis of differentially expressed inflammatory genes in coronary and carotid plaques predicted cooperative involvement of NF- $\kappa \mathrm{B}$, STATs, and IRFs (on ISRE, GAS, ISRE/GAS, ISRE/ $\mathrm{NF}-\kappa \mathrm{B}$ or GAS/NF- $\kappa \mathrm{B}$ binding sites) in regulation of their expression in different cell types present in human atherosclerotic plaques (Figure 2) [74, 86].

\section{STATs AND IRFs IN CVDS}

Agrawal et al. identified STAT1 as an important regulator of foam-cell formation and atherosclerotic lesion development in an intraperitoneal inflammation model and an atherosclerosis-susceptible bone marrow transplantation mouse model [87]. Thus STAT1 was recognized to play a role in $\mathrm{MC}$ apoptosis, a critical process for the formation of the necrotic core in atherosclerotic plaques. Mice transplanted with STAT1 deficient bone marrow revealed reduced MC apoptosis and plaque necrosis [88]. Increased activity of STAT1 protein was associated with contractile genes decreased expression, assessed with RT-PCR and Western blot assays, and as a consequence SMCs de-differentiation [89]. Increased STAT1 activity also resulted in VSMCs proliferation and neointimal hyperplasia [90]. Moreover, phosphorylated STAT1 in VSMCs and ECs of human atherosclerotic plaques correlated with elevated gene and protein expression of the chemokines CXCL9 and CXCL10 (estimated by RT-PCR 
Table 3: Natural products with STAT cross-binding activity

\begin{tabular}{|c|c|c|}
\hline Natural product & Role in STAT inhibition & References \\
\hline Cryptotanshinone & $\begin{array}{ll}- & \text { Targeting STAT3 SH2 domain } \\
\text { - } & \text { Inhibits STAT3-STAT3 dimerization }\end{array}$ & {$[131]$} \\
\hline Cucurbitacin $E$ & $\begin{array}{ll} & \text { Targeting JAK2, VEGFR2, STAT3 } \\
\text { - } & \text { Inhibits phosphorylation of STAT3 }\end{array}$ & {$[174]$} \\
\hline Cucurbitacin $Q$ & $\begin{array}{ll} & \text { Targeting STAT3 } \\
\text { - } & \text { Inhibits phosphorylation of STAT3 }\end{array}$ & {$[175]$} \\
\hline Curcumin & $\begin{array}{ll} & \text { Targeting JAK1, JAK2, JAK3, STAT3 } \\
\text { - } & \text { Inhibits phosphorylation of STAT3 }\end{array}$ & {$[173]$} \\
\hline FLLL32 & $\begin{array}{ll} & \text { Targeting STAT3 SH2 domain } \\
- & \text { Inhibits STAT3-STAT3 dimerization } \\
\end{array}$ & {$[176]$} \\
\hline LLL12 & $\begin{array}{ll}\text { - } & \text { Targeting STAT3 SH2 domain } \\
\text { - } & \text { Inhibits STAT3-STAT3 dimerization } \\
\end{array}$ & {$[177]$} \\
\hline Resveratrol & $\begin{array}{ll}\text { - } & \text { Targeting JAK1, STAT3 } \\
\text { - } & \text { Inhibits phosphorylation of STAT3 }\end{array}$ & {$[178]$} \\
\hline
\end{tabular}

and ELISA assays) [74]. STAT1 also promotes oxidative stress and tissue injury by stimulation of NADPH oxidase gene and protein expression measured by lucigeninenhanced luminescence, RT-PCR and Western blot [91], summarized in Table 1. Genetic evidence linking STAT2 protein to CVDs or myocardial infarction risk in humans has not yet been reported. However, genetic manipulation of the ApoF/Stat2 locus supports an important role for STAT2-dependent type I interferon signaling and gene expression in atherosclerosis [92], summarized in Table 1. STAT3 is activated in response to mitogenic stimuli in different cell types in vitro and invascular diseases in vivo models, but also in patients developing cardiovascular events [93]. This activation leads to functional changes in numerous cell types which acquire more undifferentiated and activated phenotype and contribute to vascular lesion formation. Indeed, Zhou et al. observed increased STAT3 phosphorylation in atherosclerotic lesions of $\mathrm{ApoE}^{-/-}$mice held on a cholesterol-rich diet, what confirms significant role of STAT3 protein in atherosclerosis progression [94]. STAT3 phosphorylation promotes upregulation of adhesion molecules ICAM-1, VCAM-1 and E-selectin in ECs, which further recruit inflammatory cells to the vessel wall $[95,96]$, summarized in Table 1.

Accumulating evidence also suggests a role of IRFs in CVDs development [14]. For example, Wessely et al. revealed an important role of IRF1 protein in neointimal growth after vessel injury and suggested IRF1 as a target for interventions to prevent hyperplasia [97]. Jiang et al. proposed that IRF1 directly activates iNOS in response to stress conditions. Mice overexpressing this transcription factor had increased ventricular dilation and fibrosis [98]. IRF1 is involved in vascular remodeling as well as contributes to exacerbation of ischaemic stroke $[99,100]$, summarized in Table 1.

Döring et al. revealed that IRF $8^{-/}$bone marrow transplantation into $\mathrm{ApoE}^{-/-}$deficient mice exacerbated atherosclerotic lesion formation [101]. Coronary heart disease in systemic lupus erythematosus (SLE) is associated with a polymorphism of the IRF8 gene [102]. Other studies reported that expression of IRF8 protein levels (Western blot) was significantly elevated in response to mechanical injury of the carotid artery. VSMCs-specific IRF8 over expression exacerbated VSMCs phenotypic switching and neointima formation, while its absence induced opposite results [100]. IRF8 also induces macrophages phenotype switch-M1 macrophages are enriched in progressing plaques, express a high level of pro-inflammatory cytokines and contribute to the progression of cardiovascular disease [103, 104]. On the other hand Jiang et al. reported that pressure overload induced cardiac hypertrophy was aggravated in mice lacking IRF8 suggesting that IRF8 is a negative regulator of pathological cardiac hypertrophy [105], summarized in Table 1.

As such, STAT1, STAT2 and STAT3 and IRF1 and IRF8 have been recognized as prominent modulators of inflammation, especially in immune and vascular cells during atherosclerosis as summarized in Table 1. Based on this, these proteins represent interesting therapeutic targets and targeted inhibition could be an interesting novel treatment strategy in CVD.

\section{CURRENT STAT INHIBITORY STRATEGIES}

STAT inhibitory strategies are actively pursued and focus on direct and indirect STAT inhibition. Drugs directly binding to STAT monomers and/or dimers comprise: oligomerization inhibitors ( $\alpha$-helix peptide analogs and lipopeptides, selectively interacting with $\mathrm{N}$-terminal domain), dimerization inhibitors (synthetic small molecules, natural products, phosphopeptides and peptidomimetics, disrupting pTyr-peptide-SH2 domain interactions), DNA-binding competitive inhibitors (oligodeoxynucleotide decoys, metal-chelating complexes, peptide aptamers and PTD-peptide conjugates) [106- 
Table 4: The most effective STAT3 signaling modulators with influence on vascular cell function (adapted from [93])

\begin{tabular}{|c|c|c|c|}
\hline Compound name & Role in STAT3 inhibition & Clinical indication & References \\
\hline \multicolumn{4}{|c|}{ FDA approved, targeting STAT3 upstream signaling } \\
\hline Ruxolitinib & $\begin{array}{|ll|}- & \text { Small molecule targeting JAK1/2 } \\
\text { Inhibits phosphorylation of } \\
\text { STAT3 }\end{array}$ & 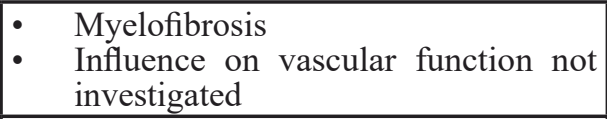 & {$[163]$} \\
\hline Tocilizumab & 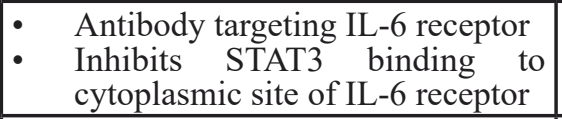 & $\begin{array}{ll}- & \text { Rheumatoid arthritis } \\
\text { - } & \text { Inhibits tumor angiogenesis }\end{array}$ & {$[179]$} \\
\hline Tofacitinib & $\begin{array}{|ll|}- & \begin{array}{l}\text { Small molecule targeting JAK3 } \\
\text { (pan-JAK effect) }\end{array} \\
\text { Inhibits phosphorylation of } \\
\text { STAT3 }\end{array}$ & $\begin{array}{ll}- & \text { Rheumatoid arthritis } \\
- & \text { Inhibits tumor angiogenesis }\end{array}$ & {$[180]$} \\
\hline \multicolumn{4}{|l|}{ Clinical Trial tested } \\
\hline$A Z D 1480$ & $\begin{array}{lll}- & \text { Small molecule targeting JAK1/2 } \\
\text { - } & \text { Inhibits phosphorylation of } \\
\text { STAT3 }\end{array}$ & $\begin{array}{l}\text { Hepatocellular carcinoma, lung } \\
\text { carcinoma and gastric cancer-- } \\
\text { NCT01219543 (Phase I) and } \\
\text { NCT01112397 (Phase I) } \\
\text { Essential thrombocythaemia } \\
\text { myelofibrosis and post- } \\
\text { polycythaemia vera-NCT00910728 } \\
\text { (Phase I) } \\
\text { - Inhibits tumor angiogenesis } \\
\end{array}$ & {$[181]$} \\
\hline $\begin{array}{l}\text { Fedratinib (SAR302503, } \\
\text { TG101348) }\end{array}$ & 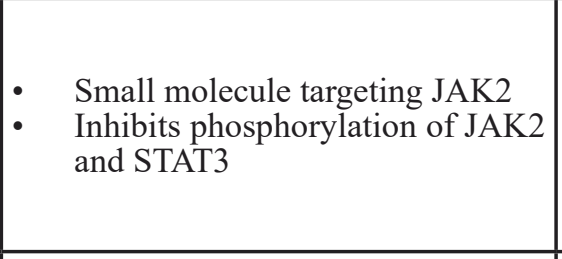 & \begin{tabular}{|l|} 
Myelofibrosis -NCT01692366, \\
NCT01437787(Phase II/III), \\
neoplasm malignant -NCT01836705 \\
(Phase I)and solid tumors - \\
NCT01585623 (Phase I) \\
Inhibition of tumor angiogenesis \\
currently being assessed
\end{tabular} & {$[182]$} \\
\hline STAT3-ODN & 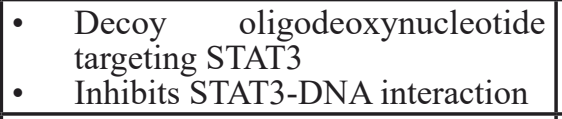 & 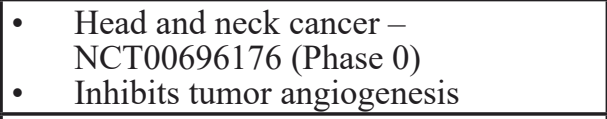 & {$[183]$} \\
\hline WP1066 & $\begin{array}{|ll|}- & \text { Small molecule targeting JAK2 } \\
\text { - } & \text { Inhibits phosphorylation of } \\
\text { STAT3 }\end{array}$ & $\begin{array}{l}\text { Brain cancer, CNS neoplasms, } \\
\text { melanoma, solid tumors - } \\
\text { NCT01904123 (Phase I) } \\
\text { Inhibits neointima formation and } \\
\text { tumor angiogenesis, contributes to } \\
\text { atherosclerotic plaque stability } \\
\end{array}$ & {$[184]$} \\
\hline \multicolumn{4}{|l|}{ pre-Clinical Trial tested } \\
\hline STATTIC & $\begin{array}{|ll|}\text { - } & \text { Small molecule targeting STAT3- } \\
\text { SH2 domain } \\
\text { Inhibits phosphorylation of } \\
\text { STAT3 }\end{array}$ & $\begin{array}{l}\text { Inhibits neointima formation, tumor } \\
\text { angiogenesis and vascular dysfunction }\end{array}$ & {$[114]$} \\
\hline S3I-201 & 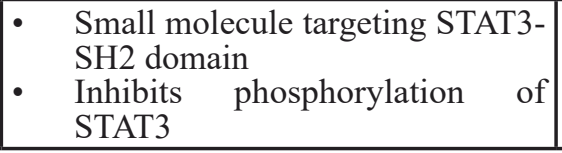 & $\begin{array}{l}\text { - Inhibits tumor angiogenesis and } \\
\text { vascular dysfunction }\end{array}$ & {$[114,185]$} \\
\hline
\end{tabular}

108]. Indirect influence on STAT activation involves: inhibition of STAT expression (antisense oligonucleotides and siRNAs), inhibition of STAT activation upstream at the receptor site (receptor/ligand antagonists and receptor-neutralizing antibodies), prevention of STAT phosphorylation (tyrosine and serine kinase inhibitors) and nuclear translocation (inhibitors of nuclear uptake of active STAT dimers) [106, 107, 109].

Searches for STAT3-targeting compounds, exploring the pTyr-SH2 interaction area of STAT3, are numerous and yielded many synthetic small molecules (over 100 compounds). Among the most potent are STA-21, STATTIC, STX-0119 and OPB-31121, which already entered clinical trials phase or show promising results in pre-clinical experiments on mice. STA-21, discovered by structure-based virtual screening, has been one of the first reported small inhibitors [110]. It inhibits STAT3 dimerization, DNA binding, and STAT3-activated luciferase reporter activity in breast cancer cells [110-112]. Moreover, STA-21 has been clinically tested for its topical efficacy on psoriasis (NCT01047943, Phase I/II) [111]. Another small molecule, STATTIC, discovered by high 
throughput screening [113], has shown to potently inhibit activation, dimerization, nuclear translocation of STAT3, and to increase apoptosis in STAT3-expressing cancer cell lines. STATTIC has led to a profound chemoradiotherapysensitization in a subcutaneous SW837 (human colon carcinoma cell line) xenograft model in mice [113115]. STX-0119, a small-molecule inhibitor of STAT3 dimerization, discovered by virtual screening [116], was able to suppress the growth of SCC3 cells (human lymphoma cell line with highly activated STAT3), through apoptosis and down-regulation of STAT3 targets such as c-myc, cyclin D1, survivin and Bcl-xL. STX-0119 also demonstrated potent antitumor effects in vivo in SCC3bearing nude mice by way of the down-regulation of STAT3 target genes and induction of apoptosis in the tumors [117]. OPB-31121 from the compound library of antifibrotic agents [118] and one of the first orally administrated STAT3-targeting compounds, was reported to strongly inhibit STAT3 phosphorylation without upstream kinase inhibition. An immunodeficient mouse transplantation model showed the significant antitumor effect of orally administrated OPB-31121 against primary human leukemia cells and its safety for normal human cord blood cells [119]. OPB-31121 also displayed antitumor effect in SCID mice bearing-tumors arising from SNU484 gastric cancer cells [120]. Currently it has been tested in clinical trials for: solid tumors (NCT00955812 and NCT00657176, Phase I); non-Hodgkin`s lymphoma and multiple myeloma (NCT00511082, Phase I); hepatocellular carcinoma (NCT01406574, Phase I/II) and leukemia (NCT01029509, Phase I).

In contrast, there are few inhibitory strategies for other STATs (1, 4, 5A/B and 6) and none for STAT2 [121128]. So far only three of these compounds entered clinical trials phase as potential STAT inhibitors. Pravastatin (potential STAT1 inhibitor) has already been approved by FDA for lowering cholesterol and preventing CVDs [94, 125]. Pimozide (potential STAT5A/B inhibitor) also FDA approved, is used in treatment of Tourette's syndrome [127]. Natural product cinnamon bark (potential STAT4 inhibitor) is in clinical trials phase for polycystic ovary syndrome (Phase I), hypercholesterolemia and type 2

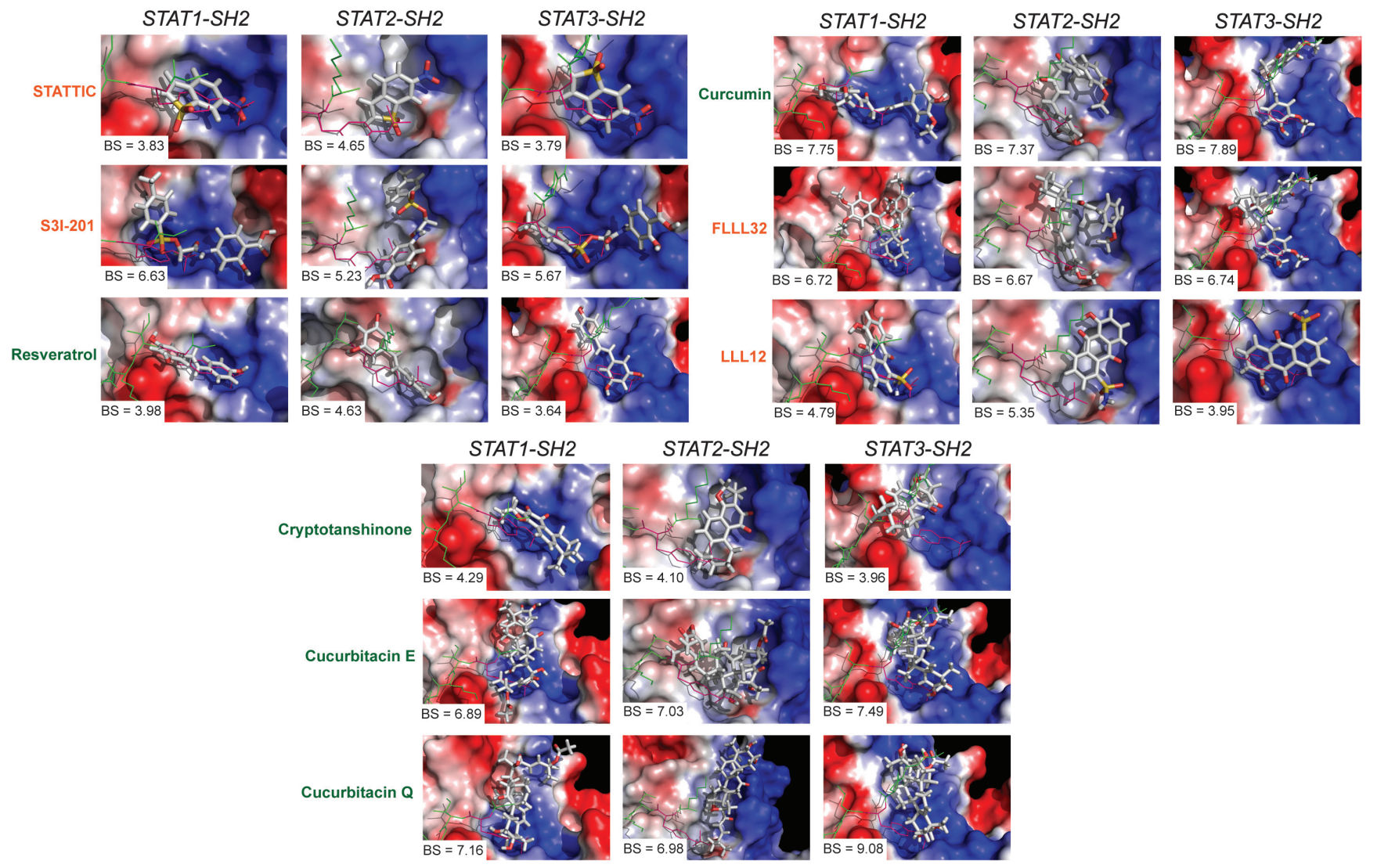

Figure 3: Natural and synthetic compounds with human STAT cross-binding activity. Binding top-scored conformations of hSTAT3 inhibitors in the SH2 domain of hSTAT1, hSTAT2 and hSTAT3 with corresponding binding score (BS) values. Natural products are colored in dark green and synthetic compounds in dark orange. All inhibitors are shown in stick representation; pTyr-linker is presented as lines colored in green with pTyr residue colored in pink. hSTAT-SH2 domains are in the surface representation, colored according to the distribution of the electrostatic surface potential, calculated with APBS [186]. Blue indicates positively charged regions, red indicates negatively charged regions. Results were obtained using Surflex-Dock 2.6 program [187]. 
diabetes (Phase II) [126].

Natural products have also been an important resource in STAT3 inhibitor discovery and these efforts have yielded several lead candidates, including capsaicin [129], curcumin [130], cryptotanshinone [131] and resveratrol [132]. They have been tested in clinical trials phase for the treatment of cancer, like curcumin: pancreatic cancer (Phase II/III), colon cancer (Phase I/II/ III), breast cancer (Phase II), head and neck cancer (Phase 0 ), osteosarcoma (Phase I/II), multiple myeloma (Phase II), and resveratrol: colorectal cancer (Phase I), follicular lymphoma (Phase II). The use of natural compounds in

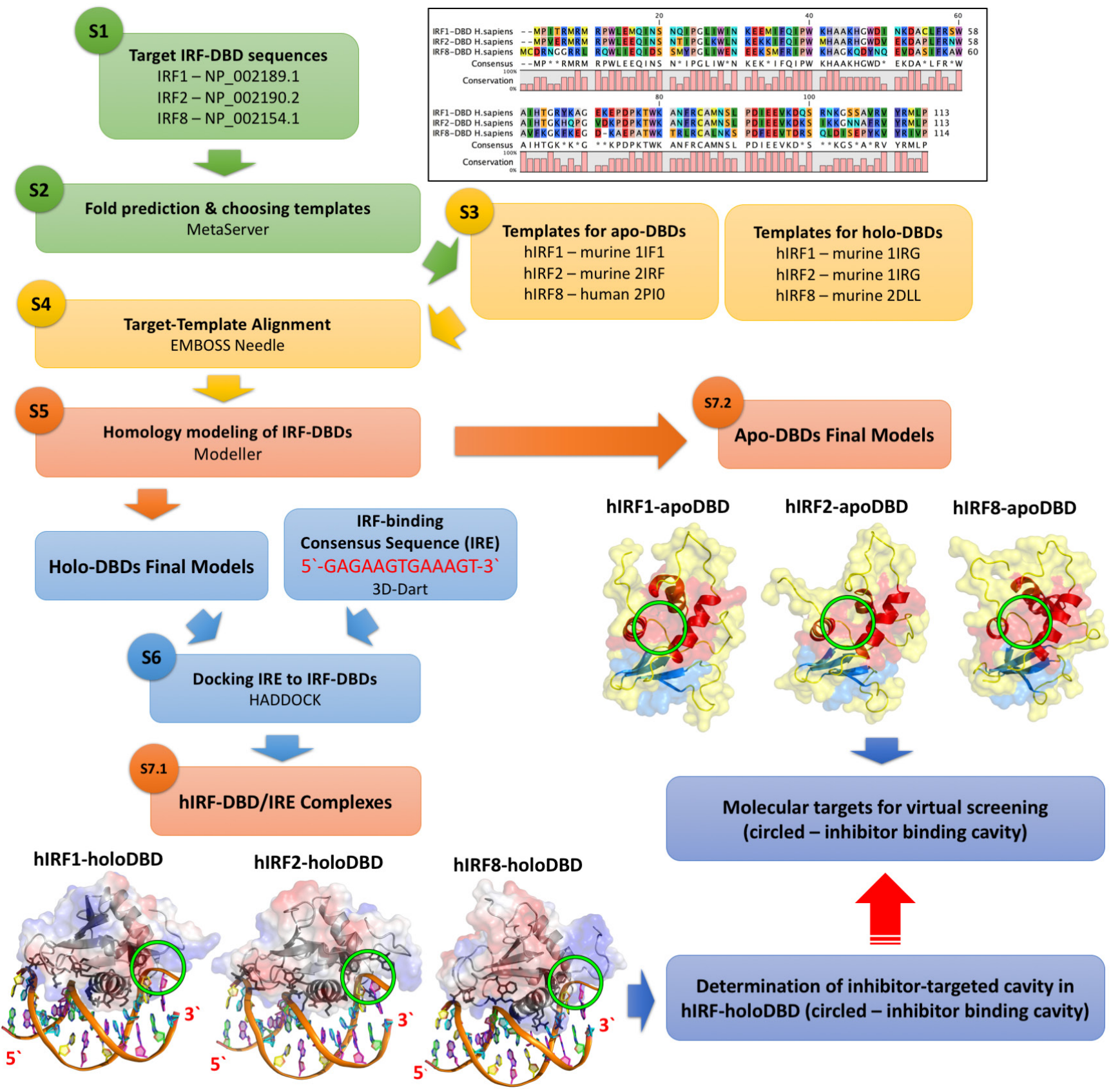

Figure 4: Comparative IRF-DBD modeling and virtual screening strategy. (S1) H. sapiens target sequences from NCBI Protein Database: IRF1 - NP_002189. 1, IRF2 - NP_002190. 2 and IRF8 - NP_002154. 1; (S2) Fold recognition - GeneSilico Metaserver [188]; (S3) Templates of cytoplasmic IRF-DBDs not-bound to DNA (apo-forms) $[156,158]$ and nuclear IRF-DBDs in complex with DNA (holo-forms) [24, 157, 159]; (S4) Target-Template Alignment -EMBOSS Needle [189]; (S5) hIRF-DBD homology modeling - Modeller [160]; (S6) protein-DNA docking - 3D-Dart [190] and HADDOCK [161]; (S7. 1) Final human IRF-holoDBD/IRE complexes models used for finding potential inhibition target cavity with Natural Products; (S7. 2) Final human IRF-apoDBD models used as the molecular targets in the comparative virtual screening strategy. 
clinical trials for other diseases than cancer has also been reported (summarized in Table 2). In many of these cases, however, the mechanism of action with regard to STAT3 activity is unclear and they are likely to block several targets. Original reports on majority of STAT3 natural inhibitors describe their simultaneous effect on hSTAT3$\mathrm{Tyr}^{705}$ phosphorylation and on related tyrosine kinases as JAK or Src. [53, 133, 134].

The number of small compound inhibitors of STATs is growing steadily. Updated information on novel STAT modulatory strategies are provided almost every year in the literature since 2007 [106-108, 135-137]. Further details are however beyond the scope of this review.

\section{Cross-binding characteristics of STAT inhibitors}

To increase our understanding of the molecular basis of STAT-SH2 pTyr contacts and small compound inhibitor interactions, we recently generated new 3D structure models for all human STATs $(1,2,3,4,5 \mathrm{~A}, 5 \mathrm{~B}$ and 6) [138]. By using a comparative in silico docking strategy we obtained further insight into STAT-SH2 crossbinding specificity of a pre-selection of fourteen STAT3 inhibitors, including the most potent natural and synthetic compounds [138].

Natural compounds selected in our study were originally discovered to be modulators of STAT3 signaling with the effect on STAT3 phosphorylation and/or STAT3STAT3 dimerization inhibition, as summarized in Table 3. Moreover, for some of them (curcumin, FLLL32 and LLL12) it was proved by molecular docking, that they fit in the functional cavities of STAT3-SH2 domain $[139,140]$. However, the real relationship between the molecular structures and the STAT3 inhibitory activity of these compounds is yet to be established. We were the first to provide an insight into their STAT-SH2 binding properties using in silico studies and determine their STAT3 specificity. Similar to STATTIC [138], the majority of these compounds primarily targeted the highly conserved pTyr-SH2 binding pocket of all STATs. Moreover, based on the binding affinity scores (BS) and graphic representation in the SH2 domain of hSTAT1, hSTAT2 and hSTAT3-SH2, we conclude that none of these compounds are STAT3-specific, as presented in Figure 3. Interestingly, smaller compounds, like LLL12 and resveratrol, were shown to predominantly target only the pTyr-binding cavity, analogous to STATTIC (Figure 3). In contrast, compounds with higher molecular weight, including STX-0119 (not shown), S3I-201, curcumin, cucurbitacin E, cucurbitacin Q, cryptotanshinone and FLLL32 covered additional $\mathrm{SH} 2$ cavities for binding (Figure 3).

Our comparative docking simulations correspond to the experimental studies of Bill et al. who proved the non-specificity of curcumin towards STAT3 and provided evidence of its cross-binding to STAT3 and STAT1
[140]. This also accounted for other natural products like cryptotanshinone [131] and resveratrol analogs (RSVA314 and RSVA405) [141]. Moreover, in silico binding of STATTIC [142] and STX-0119 (not shown) was confirmed in vitro by monitoring the effect on IFN $\alpha$ induced phosphorylation of different STATs (hSTAT1, hSTAT2 and hSTAT3), and offers a molecular explanation for these STAT cross-binding properties.

\section{CURRENT IRF INHIBITORY STRATEGIES}

IRF inhibitory strategies are mainly limited to indirect modulation of their expression and function. Selective targeting of gene expression by siRNAs (IRF1, 2, 3, 5 and 7) or miRNA-mimics (IRF4) has been used to study their antiviral activity [143-146] and correlation to different types of cancer (leukemia, multiple myeloma and ductal carcinoma) [147-149]. Upstream indirect modulation of IRF activation was observed using synthetic compounds (IRF1 - HS-Cf [150], IRF3 - LY294002 [151], IRF4 - simvastatine [152]), natural products (IRF3 piceatannol [153]) and antibiotics (IRF7 - trichostatin A [154], IRF1 - minocycline [155]). However, the influence of these compounds on IRF function is complex and involves multiple targets (e. g. inhibition of tyrosine kinases, ligand/receptor interactions and impairing formation of signal transducing complexes).

So far, no direct inhibitory strategies, utilizing virtual and/or high throughput screening of synthetic or natural compounds, and targeting the DNA binding domain of IRFs have been reported in the literature.

\section{Homology modeling of human IRF DNA binding domain}

For better understanding the interaction of IRF1 and IRF8 with their target sequence we decided to generate 3D structure models for human IRF1 and IRF8-DBD in complex with the IRE DNA (consensus sequence: 5'-GAGAAGTGAAAGT-3`). As a comparison, the protein-DNA interaction site was also determined for hIRF2-DBD. Although crystal structures of IRF1 and IRF2 DBD bound DNA (holo-forms) and NMR structure of free IRF2-DBD (apo-form) are available in the literature $[24,156,157]$, the derived amino acid sequences of these crystal structures come from Mus musculus and are not complete. According to the methods outlined in Figure 4, we built complete models of hIRF1-DBD, based on the M. musculus 1IF1 crystal structure [24] for holo-form and M. musculus 1IRG NMR structure for apo-form [156]; of hIRF2-DBD, based on M. musculus 2IRF for holo-form [157] and M. musculus 1IRG NMR for apo-form [156] (Figure 4). Because the crystal structure of hIRF8-DBD has not been solved to date, a homology model of the H. sapiens apo DBD counterpart (based on M. musculus 
2DLL [158]) of this protein as well as holoDBD (based on $H$. sapiens 2PI0 [159]) in complex with the IRE were generated (using Modeller [160] and HADDOCK [161] software) and we are the first to present them (Figure 4).
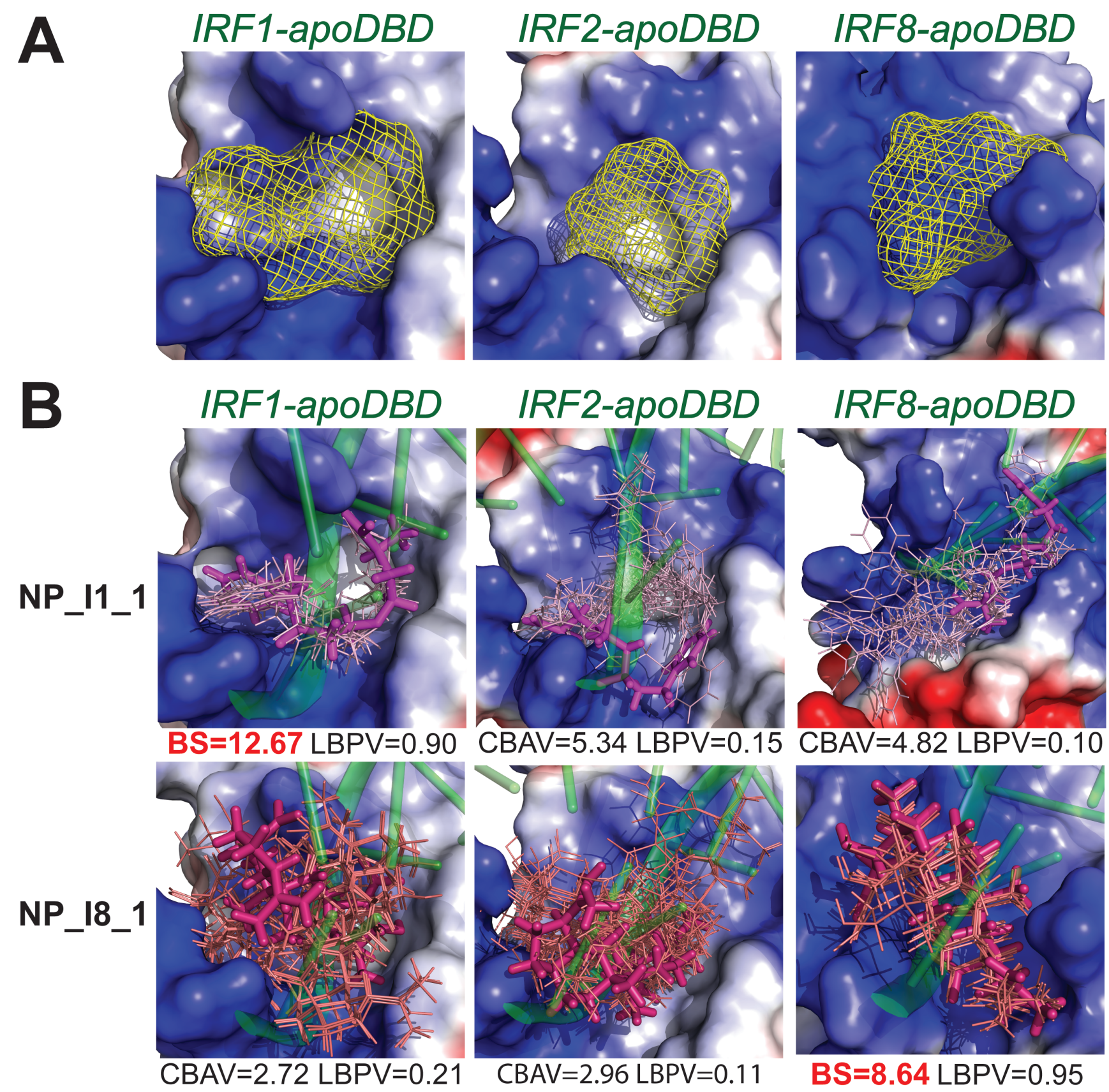

$B S=8.64 \mathrm{LBPV}=0.95$

Figure 5: Binding conformations of compounds from Natural Products ZINC database subset in the hIRF1, hIRF2 and hIRF8 DNA-binding domain. A. The target pocket for virtual screening with an idealized active-site ligand (protomol) in the DBD of hIRF1, hIRF2 and hIRF8 non-bound with DNA (apo-form). Protomol is based on the interaction plane between DNA and amino acid residues of the respective hIRF-DBD/IRE complexes (holo-form). The protomol surface is shown in mesh representation and colored in yellow. B. Twenty binding pose variations of top-scored hIRF1-specific (NP_I1_1) and hIRF8-specific (NP_I8_1) inhibitor in apoDBD domain of hIRF1, hIRF2 and hIRF8. The best binding conformation (with the highest BS) is shown in stick representation and the remaining binding pose variations are shown in line representation. hIRF1, hIRF2 and hIRF8 apoDBDs are in the surface representation, colored according to the distribution of the electrostatic surface potential, calculated with APBS [186]. Blue indicates positively charged regions, red indicates negatively charged regions. dsDNA fragment of the respective hIRF-holoDBD/IRE complexes is shown in transparent cartoon representation and colored in green. Ligand docking results were obtained using Surflex-Dock 2. 6 program [187]. 


\section{Identification of IRF1 and IRF8 potential inhibitors by comparative virtual screening of natural compounds}

Based on the methodology described for the comparative docking of STAT-specific inhibitors, we applied an in silico hIRF-DBD comparative virtual screening strategy for commercially available subset of Natural Products from ZINC Database (131 582 compounds) to identify specific IRF1 or IRF8 inhibitors (Figure 5 and Szelag et al., manuscript in preparation). For this purpose, we modeled apo-forms of hIRF1, hIRF2 and hIRF8-DBD (not-bound to DNA), which were further used as the molecular targets of our virtual screening strategy (Figure 5A). The standard selection criteria of these compounds are based on those developed for STAT virtual screening $[138,162]$ and include the 'IRFcomparative binding affinity value' (IRF-CBAV) and 'ligand binding pose variation' (LBPV) parameters. CBAV is a measure of the binding quality between different IRFs and LBPV reflects the binding specificity. The five step docking procedure, subsequently resulted in a list of 20 optimized conformations for each selected compound, with supporting binding score values (BS), CBAVs and LBPVs for each IRF. Consequently, we obtained 60 top hits for hIRF1-DBD and 7 top hits for hIRF8-DBD (not shown). This is further illustrated in Figure 5B, in which the top 20 optimized binding conformations for NP I1 1 and NP I8 1 are depicted in the DBD of hIRF1, hIRF2 and hIRF8, as a graphical representation of LBPV. As a representative hIRF1 specific compound, with (IRF1IRF2)-CBAV of 5.34 and (IRF1-IRF8)-CBAV of 4. 82, NP_I1_1 has hIRF1-LBPV of 0.9 and subsequent high conformational conservation within hIRF1-DBD. In hIRF2 and hIRF8 DBD, however, its LBPV is close to 0.1 , which corresponds to low conformational conservation. Likewise, NP_I8_1 displays high conformational conservation towards hIRF8-DBD, but low conservation with respect to hIRF1 and hIRF2-DBD (Figure 5B).

\section{POTENTIAL APPLICATIONS OF STAT AND IRF INHIBITORS IN CVD}

Targeting the STAT3 pathway is an upcoming therapeutic approach in the treatment of a rising number of inflammatory or proliferative diseases, e. g. psoriasis, myelofibrosis, myeloproliferative disorders, rheumatoid arthritis, and colitis ulcerosa, which also have an effect on vascular cell function [93, 163-167]. Patients who suffer from these autoimmune diseases are at high risk of developing atherosclerosis and CVDs due to abnormal activity of the immune system. Promising results for several FDA-approved (Ruxolitinib, Tocilizumab, Tofacitinib) or (pre)Clinical Trial tested (AZD1480, Fedratinib, STAT3-ODN, WP1066, STATTIC and S3I-
201) inhibitors, predicts STAT3-inhibiting strategies to find their way to the clinic in the near future (Table 4) [93]. Thus, they could serve as therapeutics preventing life-threatening complications (i. e. myocardial infarction and stroke) and as protectors from vascular dysfunction, associated with many diseases. The same is true for a selection of STAT3 inhibiting natural compounds, including capsaicin, curcumin, cryptotanshinone and resveratrol that have numerous clinical implications (summarized in Table 2) [106].

$$
\text { Recently, Johnson et al. provided }
$$

the first evidence that inhibitors of STAT3 activation protect against AngII-induced oxidative stress, endothelial dysfunction, and hypertension in mice. Incubation of isolated carotid arteries from C57BL/6J mice with AngII overnight increased superoxide and reduced vasodilator responses to the endotheliumdependent agonist acetylcholine. These effects were prevented by the addition of S3I-201 or STATTIC. In vivo, administration of AngII increased arterial pressure, and this effect was prevented by S3I-201 treatment. After systemic treatment with AngII, dilator responses to acetylcholine were reduced in carotid artery and basilar arteries, whereas S3I-201 treatment prevented most of this impairment. In contrast, S31-201 did not prevent AngIIinduced hypertrophy in the carotid artery [114]. Because AngII promotes vascular disease in the presence of multiple cardiovascular risk factors, the authors suggested that selective targeting of STAT3 might have substantial therapeutic potential. Because we proved that S3I-201 and STATTIC are not STAT3-specific, an additional role of other STATs in Ang II-induced vascular dysfunction and hypertension cannot be ruled out. Indeed, evidence in the literature points to the involvement of STAT1 [168172], whereas that of STAT2 is currently not known. At the same time we were able to proof that treatment of VSMCs with IFN $\gamma$ and LPS in the presence of the JAK2 inhibitor AG490 and STATTIC resulted in potent inhibition of the pro-inflammatory and pro-atherogenic genes Cxc19, Cxcl10, Cc15, Nos2, IFIT1 and OAS2 (not shown). Under these conditions, multiple transcription factors, including NF-אB, STAT1, STAT2, IRF1 and IRF8 are involved in the regulation of expression of all of these genes in a combinatorial fashion (see paragraph 3.1 and 3. 2) $[65,74,86]$. Thus, AG490 and STATTIC effectively attenuate cross-talk between IFN $\gamma$ and LPS. (Szelag et al. , manuscript in preparation). Together with our in silico STAT-SH2 docking studies of selected non-specific STAT3 inhibitors (Figure 3), we propose their potential of targeting cooperative involvement of NF- $\mathrm{KB}$, STATs, and IRFs (on ISRE, GAS, ISRE/GAS, ISRE/NF- $\kappa B$ or GAS/NF- $\kappa$ B binding sites: see Figure 2) in regulation of crucial pro-inflammatory and pro-atherogenic target genes as a novel clinical application in CVDs apart from their established role in cancer treatment and prevention. In a similar fashion, the IRF homology modeling procedure, 
creating DBD and IAD models for all IRFs, will allow to perform in silico IRF-DBD and IRF-IAD comparative virtual screening and identify potential specific or non specific IRF inhibitors for clinical applications of CVD.

\section{FUTURE PERSPECTIVES}

Recent evidence provides support for the idea that STAT1, STAT2 and STAT3, and IRF1 and IRF8 are prominent modulators of inflammation, especially in immune and vascular cells during atherosclerosis. Based on this, these proteins represent interesting therapeutic targets that have a crucial role in mediating the interplay between damaged vessels and host immunity to control atherosclerosis directed by multiple inflammatory stimuli. Thus, targeted inhibition could be a novel treatment strategy in CVDs.

Promising results for several STAT3 inhibitors, including synthetic small compounds, natural products and oligonucleotide decoys, in recent (pre)clinical trials predicts STAT3-inhibiting strategies to find their way to the clinic in the near future. Many of the published STAT3 inhibitors do not seem STAT-specific, display toxicity and are not very potent. So far, only a few inhibitors for other STATs as well as IRFs have been described. This illustrates the need for better models and screening and validation tools for STAT and IRF inhibitors with high specificity, potency and excellent bioavailability.

In our effort to identify specific inhibitors for different STATs and IRFs, we developed a novel pipeline approach that combines in silico multi-million compound library screening with in vitro comparative inhibition validation [138]. This involves a five step comparative virtual screening tool, CAVS (Comparative Approach for Virtual Screening), (Figure 6). [162]. Thus, by comparative screening of a 'natural product' library (ZINC subset Natural Products) and a multi-million 'clean leads' compound library (ZINC subset Clean Leads), we provided initial in silico proof for the possible existence of STAT1, STAT2 and STAT3 as well as IRF1 and IRF8 specific inhibitors, as presented in Figure 5 [138]. Lowthroughput in vitro cell-based multiple STAT activation and IRF inhibition will be used to validate the effect of pre-selected inhibitory compounds on cytokine-induced

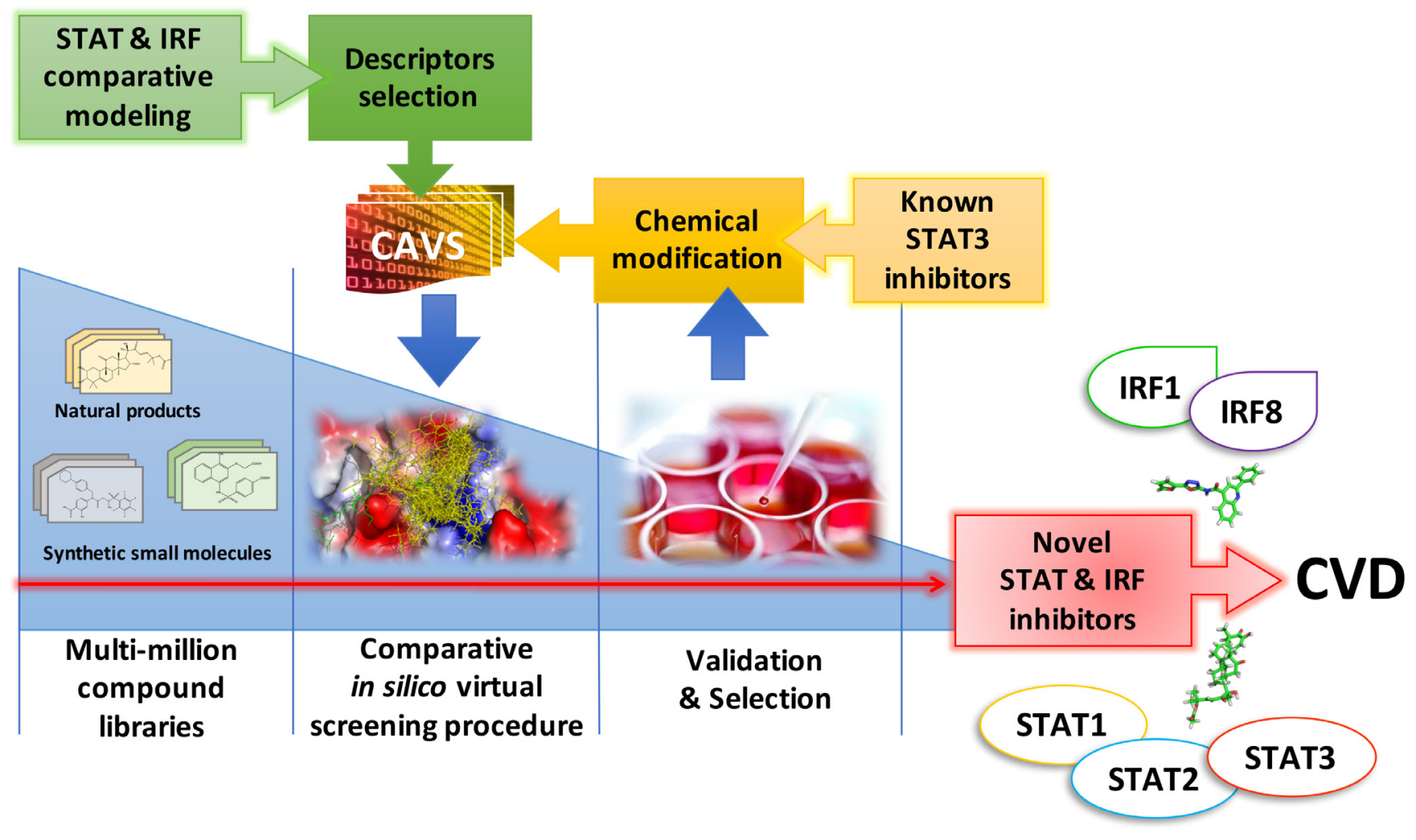

Figure 6: Comparative screening and validation pipeline approach to identify specific human STAT and IRF inhibitors in treatment of CVD. Based on 'Comparative modeling', 3D structure models for all human STATs and IRFs are used for 'Descriptor selection' to select molecular targets like DBD, SH2, IAD, or newly defined cavities. These targets enter a pipeline approach that combines comparative in silico docking (CAVS) with an in vitro activation inhibition assay, to screen multi-million compound libraries and identify specific STAT and IRF inhibitors. At the same time, already available non-specific STAT3 inhibitors are optimized by 'Chemical modification' and further selected for specificity through comparative in silico docking (CAVS) and in vitro activation inhibition. 
STAT and IRF action and target gene expression in different cell types (Figure 6).

Identification of specific and effective STAT and IRF inhibitory compounds could provide a tool to increase our understanding of the functional role of these proteins in CVDs. The further testing and optimizing of already available non-specific STAT inhibitors may be a promising avenue for new clinical benefits. On the other hand, the search for and the development of new STAT and IRF inhibitors with high specificity, potency and excellent bioavailability remains a hopeful approach for the success of combating CVDs.

\section{Abbreviations}

5W - five tryptophan repeats - 'tryptophan cluster'

AD - activation domain

Ang II- angiotensin II

AP1 - activator protein 1

ApoE - apolipoprotein E

APP - acute phase protein

BS - binding affinity score

CAVS - Comparative Approach for Virtual

Screening

CBAV - comparative binding affinity value

$\mathrm{CC}$ - coiled-coil domain

CCL19 - chemokine (C-C motif) ligand 19

$\mathrm{Ccl} 5$ - chemokine (C-C motif) ligand 5

ChIP - chromatin immunoprecipitation

CKII - casein kinase II

COP9 - constitutive photomorphogenesis 9

CSN - constitutive photomorphogenesis 9

signalosome

CVD - cardiovascular disease

Cxcl10 - chemokine (C-X-C motif) ligand 10

Cxc19 - chemokine (C-X-C motif) ligand 9

DAMP - damage-associated molecular pattern

molecule

DBD - DNA-binding domain

DC- dendritic cell

EC- endothelial cell

ELISA - enzyme-linked immunosorbent assay

FDA - Food and Drug Administration

GAS - interferon-gamma activation site

gp130 - glycoprotein 130

hIRF - human interferon regulatory factor

HMGB1- high-mobility group box 1

HSP - heat shock protein

hSTAT - human signal transducer and activator of transcription

IAD - IRF association domain

ICAM-1 - intercellular adhesion molecule 1

IDO1 - indoleamine-pyrrole 2,3-dioxygenase

IFIT1 - interferon-induced protein with

tetratricopeptide repeats 1

IFN - interferon
IFNAR - interferon- $\alpha / \beta$ receptor

IFNGR - interferon-g receptor

IL - interleukin

IL-6R - Interleukin 6 receptor

iNOS - nitric oxide synthases

IRE - IFN regulatory element

IRF- interferon regulatory factor

ISG - interferon-stimulated gene (IFN-inducible gene)

ISRE - interferon-stimulated response element

JAK - Janus kinase

LBPV - ligand binding pose variation

LK - linker domain

LPS - lipopolysaccharide

MC - macrophage

MI - myocardial infarction

MMP - matrix metalloproteinases

MyD88 - myeloid differentiation primary response 88

ND - N-terminal domain

$\mathrm{NF}-\kappa \mathrm{B}$ - nuclear factor kappa B

OAS2 - 2`-5`-oligoadenylate synthetase 2

Ox-LDL - oxidized low-density lipoprotein

PAMP - pathogen-associated molecular pattern

molecule

PCR - polymerase chain reaction

PRR - pattern recognition receptor

pTyr - phosphotyrosine

RMSD - root-mean-square deviation

SH2 - Src-homology 2 domain

SLE - systemic lupus erythematosus

SMC - smooth muscle cell

STAT - signal transducer and activator of

transcription

TAD - transcriptional activation domain

Th1 - T helper 1 lymphocytes

TIR - Toll/interleukin-1 receptor

TLR - toll-like receptor

TNF - tumor necrosis factor

TRAM - TRIF-related adaptor molecule

TRIF - TIR-domain-containing adapter-inducing interferon- $\beta$

VCAM-1 - vascular cell adhesion molecule 1

VEGF- vascular endothelial growth factor

VSMC- vascular smooth muscle cell

Y-P - phosphorylated tyrosine

\section{ACKNOWLEDGMENTS}

This publication was supported by grants UMO2012/07/B/NZ1/02710 (HB), UMO-2015/17/B/ NZ2/00967 (HB), UMO-2012/07/N/NZ2/01359 (MS), UMO-2015/16/T/NZ2/00055 (MS) from National Science Centre Poland, Grant No. 21280006 (HB) from International Visegrad Fund and No 128 from the Poznan Supercomputing and Networking Center (PSNC) (MS). 
This work was supported by the KNOW RNA Research Centre in Poznan (No. 01/KNOW2/2014) and in part by PL-Grid Infrastructure (MS).

\section{CONFLICTS OF INTEREST}

The authors confirm that this article content has no conflicts of interest. The funders had no role in study design, data collection and analysis, decision to publish, or preparation of the manuscript.

\section{REFERENCES}

1. Mathers CD and Loncar D. Projections of global mortality and burden of disease from 2002 to 2030 . PLoS medicine. 2006; 3:e442.

2. Sikorski K, Czerwoniec A, Bujnicki JM, Wesoly J and Bluyssen HA. STAT1 as a novel therapeutical target in pro-atherogenic signal integration of IFNgamma, TLR4 and IL-6 in vascular disease. Cytokine \& growth factor reviews. 2011; 22:211-219.

3. Hack $\mathrm{CE}$ and Zeerleder S. The endothelium in sepsis: source of and a target for inflammation. Critical care medicine. 2001; 29:S21-27.

4. Lusis AJ. Atherosclerosis. Nature. 2000; 407:233-241.

5. Allahverdian S, Chehroudi AC, McManus BM, Abraham $\mathrm{T}$ and Francis GA. Contribution of intimal smooth muscle cells to cholesterol accumulation and macrophage-like cells in human atherosclerosis. Circulation. 2014; 129:15511559.

6. Robertson AK and Hansson GK. T cells in atherogenesis: for better or for worse? Arteriosclerosis, thrombosis, and vascular biology. 2006; 26:2421-2432.

7. Yilmaz A, Lochno M, Traeg F, Cicha I, Reiss C, Stumpf C, Raaz D, Anger T, Amann K, Probst T, Ludwig J, Daniel WG and Garlichs CD. Emergence of dendritic cells in rupture-prone regions of vulnerable carotid plaques. Atherosclerosis. 2004; 176:101-110.

8. Bobryshev YV and Lord RS. Co-accumulation of dendritic cells and natural killer $\mathrm{T}$ cells within rupture-prone regions in human atherosclerotic plaques. The journal of histochemistry and cytochemistry. 2005; 53:781-785.

9. Libby P. Inflammation in atherosclerosis. Nature. 2002; 420:868-874.

10. Hansson GK, Robertson AK and Soderberg-Naucler C. Inflammation and atherosclerosis. Annual review of pathology. 2006; 1:297-329.

11. Levy DE and Darnell JE, Jr. Stats: transcriptional control and biological impact. Nature reviews Molecular cell biology. 2002; 3:651-662.

12. Tamura T, Yanai H, Savitsky D and Taniguchi T. The IRF family transcription factors in immunity and oncogenesis. Annual review of immunology. 2008; 26:535-584.
13. Grote K, Luchtefeld M and Schieffer B. JANUS under stress--role of JAK/STAT signaling pathway in vascular diseases. Vascular pharmacology. 2005; 43:357-363.

14. Sun $H$ and Wang Y. Interferon regulatory factors in heart: stress response beyond inflammation. Hypertension. 2014; 63:663-664.

15. Ehret GB, Reichenbach P, Schindler U, Horvath CM, Fritz $\mathrm{S}$, Nabholz $\mathrm{M}$ and Bucher P. DNA binding specificity of different STAT proteins. Comparison of in vitro specificity with natural target sites. The Journal of biological chemistry. 2001; 276:6675-6688.

16. Bonham AJ, Wenta N, Osslund LM, Prussin AJ, 2nd, Vinkemeier U and Reich NO. STAT1:DNA sequencedependent binding modulation by phosphorylation, protein:protein interactions and small-molecule inhibition. Nucleic acids research. 2013; 41:754-763.

17. Khan KD, Shuai K, Lindwall G, Maher SE, Darnell JE, Jr. and Bothwell AL. Induction of the Ly-6A/E gene by interferon alpha/beta and gamma requires a DNA element to which a tyrosine-phosphorylated $91-\mathrm{kDa}$ protein binds. Proceedings of the National Academy of Sciences of the United States of America. 1993; 90:6806-6810.

18. Horvath CM, Wen $Z$ and Darnell JE, Jr. A STAT protein domain that determines DNA sequence recognition suggests a novel DNA-binding domain. Genes \& development. 1995; 9:984-994.

19. Sadowski HB, Shuai K, Darnell JE, Jr. and Gilman MZ. A common nuclear signal transduction pathway activated by growth factor and cytokine receptors. Science. 1993; 261:1739-1744.

20. Zhong Z, Wen Z and Darnell JE, Jr. Stat3: a STAT family member activated by tyrosine phosphorylation in response to epidermal growth factor and interleukin-6. Science. 1994; 264:95-98.

21. Hengerer B, Lindholm D, Heumann R, Ruther U, Wagner $\mathrm{EF}$ and Thoenen H. Lesion-induced increase in nerve growth factor mRNA is mediated by c-fos. Proceedings of the National Academy of Sciences of the United States of America. 1990; 87:3899-3903.

22. Leong PL, Andrews GA, Johnson DE, Dyer KF, Xi S, Mai JC, Robbins PD, Gadiparthi S, Burke NA, Watkins SF and Grandis JR. Targeted inhibition of Stat 3 with a decoy oligonucleotide abrogates head and neck cancer cell growth. Proceedings of the National Academy of Sciences of the United States of America. 2003; 100:4138-4143.

23. Nehyba J, Hrdlickova R, Burnside J and Bose HR, Jr. A novel interferon regulatory factor (IRF), IRF-10, has a unique role in immune defense and is induced by the v-Rel oncoprotein. Molecular and cellular biology. 2002; 22:3942-3957.

24. Escalante CR, Yie J, Thanos D and Aggarwal AK. Structure of IRF-1 with bound DNA reveals determinants of interferon regulation. Nature. 1998; 391:103-106. 
25. Sharf R, Azriel A, Lejbkowicz F, Winograd SS, Ehrlich $\mathrm{R}$ and Levi BZ. Functional domain analysis of interferon consensus sequence binding protein (ICSBP) and its association with interferon regulatory factors. The Journal of biological chemistry. 1995; 270:13063-13069.

26. Darnell JE, Jr. , Kerr IM and Stark GR. Jak-STAT pathways and transcriptional activation in response to IFNs and other extracellular signaling proteins. Science. 1994; 264:14151421.

27. Sharf R, Meraro D, Azriel A, Thornton AM, Ozato K, Petricoin EF, Larner AC, Schaper F, Hauser H and Levi BZ. Phosphorylation events modulate the ability of interferon consensus sequence binding protein to interact with interferon regulatory factors and to bind DNA. The Journal of biological chemistry. 1997; 272:9785-9792.

28. Meraro D, Hashmueli S, Koren B, Azriel A, Oumard A, Kirchhoff S, Hauser H, Nagulapalli S, Atchison ML and Levi BZ. Protein-protein and DNA-protein interactions affect the activity of lymphoid-specific IFN regulatory factors. Journal of immunology. 1999; 163:6468-6478.

29. Penninger JM, Sirard C, Mittrucker HW, Chidgey A, Kozieradzki I, Nghiem M, Hakem A, Kimura T, Timms E, Boyd R, Taniguchi T, Matsuyama T and Mak TW. The interferon regulatory transcription factor IRF-1 controls positive and negative selection of $\mathrm{CD} 8+$ thymocytes. Immunity. 1997; 7:243-254.

30. Lin R and Hiscott J. A role for casein kinase II phosphorylation in the regulation of IRF-1 transcriptional activity. Molecular and cellular biochemistry. 1999; 191:169-180.

31. Cohen H, Azriel A, Cohen T, Meraro D, Hashmueli S, Bech-Otschir D, Kraft R, Dubiel W and Levi BZ. Interaction between interferon consensus sequence-binding protein and COP9/signalosome subunit CSN2 (Trip15). A possible link between interferon regulatory factor signaling and the COP9/signalosome. The Journal of biological chemistry. 2000; 275:39081-39089.

32. Birnbaum MJ, van Zundert B, Vaughan PS, Whitmarsh AJ, van Wijnen AJ, Davis RJ, Stein GS and Stein JL. Phosphorylation of the oncogenic transcription factor interferon regulatory factor 2 (IRF2) in vitro and in vivo. Journal of cellular biochemistry. 1997; 66:175-183.

33. Bailey CM, Abbott DE, Margaryan NV, Khalkhali-Ellis Z and Hendrix MJ. Interferon regulatory factor 6 promotes cell cycle arrest and is regulated by the proteasome in a cell cycle-dependent manner. Molecular and cellular biology. 2008; 28:2235-2243.

34. Biswas PS, Gupta S, Chang E, Song L, Stirzaker RA, Liao JK, Bhagat $G$ and Pernis AB. Phosphorylation of IRF4 by ROCK 2 regulates IL-17 and IL-21 production and the development of autoimmunity in mice. The Journal of clinical investigation. 2010; 120:3280-3295.

35. Lopez-Pelaez M, Lamont DJ, Peggie M, Shpiro N, Gray
NS and Cohen P. Protein kinase IKKbeta-catalyzed phosphorylation of IRF5 at Ser462 induces its dimerization and nuclear translocation in myeloid cells. Proceedings of the National Academy of Sciences of the United States of America. 2014; 111:17432-17437.

36. Xu XH, Shah PK, Faure E, Equils O, Thomas L, Fishbein MC, Luthringer D, Xu XP, Rajavashisth TB, Yano J, Kaul S and Arditi M. Toll-like receptor-4 is expressed by macrophages in murine and human lipid-rich atherosclerotic plaques and upregulated by oxidized LDL. Circulation. 2001; 104:3103-3108.

37. Methe H, Kim JO, Kofler S, Weis M, Nabauer M and Koglin J. Expansion of circulating Toll-like receptor 4-positive monocytes in patients with acute coronary syndrome. Circulation. 2005; 111:2654-2661.

38. Michelsen KS, Wong MH, Shah PK, Zhang W, Yano J, Doherty TM, Akira S, Rajavashisth TB and Arditi M. Lack of Toll-like receptor 4 or myeloid differentiation factor 88 reduces atherosclerosis and alters plaque phenotype in mice deficient in apolipoprotein E. Proceedings of the National Academy of Sciences of the United States of America. 2004; 101:10679-10684.

39. Cani PD, Amar J, Iglesias MA, Poggi M, Knauf C, Bastelica D, Neyrinck AM, Fava F, Tuohy KM, Chabo C, Waget A, Delmee E, Cousin B, Sulpice T, Chamontin B, Ferrieres J, et al. Metabolic endotoxemia initiates obesity and insulin resistance. Diabetes. 2007; 56:1761-1772.

40. Amar J, Burcelin R, Ruidavets JB, Cani PD, Fauvel J, Alessi MC, Chamontin B and Ferrieres J. Energy intake is associated with endotoxemia in apparently healthy men. Am J Clin Nutr. 2008; 87:1219-1223.

41. Szeto CC, Kwan BC, Chow KM, Lai KB, Chung KY, Leung $\mathrm{CB}$ and Li PK. Endotoxemia is related to systemic inflammation and atherosclerosis in peritoneal dialysis patients. Clin J Am Soc Nephrol. 2008; 3:431-436.

42. Laugerette F, Vors C, Peretti N and Michalski MC. Complex links between dietary lipids, endogenous endotoxins and metabolic inflammation. Biochimie. 2011; 93:39-45.

43. Lu Z, Zhang X, Li Y, Jin J and Huang Y. TLR4 antagonist reduces early-stage atherosclerosis in diabetic apolipoprotein E-deficient mice. J Endocrinol. 2013; 216:61-71.

44. Cole JE, Georgiou E and Monaco C. The expression and functions of toll-like receptors in atherosclerosis. Mediators Inflamm. 2010; 2010:393946.

45. Kanellakis P, Agrotis A, Kyaw TS, Koulis C, Ahrens I, Mori S, Takahashi HK, Liu K, Peter K, Nishibori M and Bobik A. High-mobility group box protein 1 neutralization reduces development of diet-induced atherosclerosis in apolipoprotein e-deficient mice. Arteriosclerosis, thrombosis, and vascular biology. 2011; 31:313-319. 
46. Erridge C. The roles of Toll-like receptors in atherosclerosis. Journal of innate immunity. 2009; 1:340-349.

47. Kawai $\mathrm{T}$ and Akira $\mathrm{S}$. The role of pattern-recognition receptors in innate immunity: update on Toll-like receptors. Nature immunology. 2010; 11:373-384.

48. Schindler C, Levy DE and Decker T. JAK-STAT signaling: from interferons to cytokines. The Journal of biological chemistry. 2007; 282:20059-20063.

49. Wesoly J, Szweykowska-Kulinska Z and Bluyssen HA. STAT activation and differential complex formation dictate selectivity of interferon responses. Acta biochimica Polonica. 2007; 54:27-38.

50. McLaren JE and Ramji DP. Interferon gamma: a master regulator of atherosclerosis. Cytokine \& growth factor reviews. 2009; 20:125-135.

51. Levy Z, Rachmani R, Trestman S, Dvir A, Shaish A, Ravid $M$ and Harats D. Low-dose interferon-alpha accelerates atherosclerosis in an LDL receptor-deficient mouse model. Eur J Intern Med. 2003; 14:479-483.

52. Goossens P, Gijbels MJ, Zernecke A, Eijgelaar W, Vergouwe MN, van der Made I, Vanderlocht J, Beckers L, Buurman WA, Daemen MJ, Kalinke U, Weber C, Lutgens $\mathrm{E}$ and de Winther MP. Myeloid type I interferon signaling promotes atherosclerosis by stimulating macrophage recruitment to lesions. Cell metabolism. 2010; 12:142-153.

53. Noels $\mathrm{H}$ and Weber C. Catching up with important players in atherosclerosis: type I interferons and neutrophils. Current opinion in lipidology. 2011; 22:144-145.

54. Tellides G, Tereb DA, Kirkiles-Smith NC, Kim RW, Wilson JH, Schechner JS, Lorber MI and Pober JS. Interferon-gamma elicits arteriosclerosis in the absence of leukocytes. Nature. 2000; 403:207-211.

55. Leon ML and Zuckerman SH. Gamma interferon: a central mediator in atherosclerosis. Inflammation research. 2005; 54:395-411.

56. Schuett H, Luchtefeld M, Grothusen C, Grote K and Schieffer B. How much is too much? Interleukin-6 and its signalling in atherosclerosis. Thromb Haemost. 2009; 102:215-222.

57. Huber SA, Sakkinen P, Conze D, Hardin N and Tracy R. Interleukin-6 exacerbates early atherosclerosis in mice. Arteriosclerosis, thrombosis, and vascular biology. 1999; 19:2364-2367.

58. Ridker PM, Rifai N, Stampfer MJ and Hennekens CH. Plasma concentration of interleukin- 6 and the risk of future myocardial infarction among apparently healthy men. Circulation. 2000; 101:1767-1772.

59. Schrader LI, Kinzenbaw DA, Johnson AW, Faraci FM and Didion SP. IL-6 deficiency protects against angiotensin II induced endothelial dysfunction and hypertrophy. Arteriosclerosis, thrombosis, and vascular biology. 2007; 27:2576-2581.

60. Protogerou AD, Zampeli E, Fragiadaki K, Stamatelopoulos K, Papamichael C and Sfikakis PP. A pilot study of endothelial dysfunction and aortic stiffness after interleukin-6 receptor inhibition in rheumatoid arthritis. Atherosclerosis. 2011; 219:734-736.

61. Levy DE, Kessler DS, Pine R and Darnell JE, Jr. Cytoplasmic activation of ISGF3, the positive regulator of interferon-alpha-stimulated transcription, reconstituted in vitro. Genes \& development. 1989; 3:1362-1371.

62. Yuan J, Wegenka UM, Lutticken C, Buschmann J, Decker T, Schindler C, Heinrich PC and Horn F. The signalling pathways of interleukin- 6 and gamma interferon converge by the activation of different transcription factors which bind to common responsive DNA elements. Molecular and cellular biology. 1994; 14:1657-1668.

63. Guschin D, Rogers N, Briscoe J, Witthuhn B, Watling D, Horn F, Pellegrini S, Yasukawa K, Heinrich P, Stark GR, lhle JN, Kerr IM. A major role for the protein tyrosine kinase JAK1 in the JAK/STAT signal transduction pathway in response to interleukin-6. EMBO J. 1995; 14:1421-1429.

64. Li X, Leung S, Qureshi S, Darnell JE, Jr. and Stark GR. Formation of STAT1-STAT2 heterodimers and their role in the activation of IRF-1 gene transcription by interferonalpha. The Journal of biological chemistry. 1996; 271:57905794.

65. Sikorski K, Chmielewski S, Olejnik A, Wesoly JZ, Heemann U, Baumann M and Bluyssen H. STAT1 as a central mediator of IFNgamma and TLR4 signal integration in vascular dysfunction. Jak-Stat. 2012; 1:241-249.

66. Jones BW, Means TK, Heldwein KA, Keen MA, Hill PJ, Belisle JT and Fenton MJ. Different Toll-like receptor agonists induce distinct macrophage responses. Journal of leukocyte biology. 2001; 69:1036-1044.

67. Decker T, Muller M and Stockinger S. The yin and yang of type I interferon activity in bacterial infection. Nature reviews Immunology. 2005; 5:675-687.

68. O'Neill LA and Bowie AG. The family of five: TIRdomain-containing adaptors in Toll-like receptor signalling. Nature reviews Immunology. 2007; 7:353-364.

69. Honda K, Takaoka A and Taniguchi T. Type I interferon [corrected] gene induction by the interferon regulatory factor family of transcription factors. Immunity. 2006; 25:349-360.

70. Schroder K, Sweet MJ and Hume DA. Signal integration between IFNgamma and TLR signalling pathways in macrophages. Immunobiology. 2006; 211:511-524.

71. Hu X, Chen J, Wang L and Ivashkiv LB. Crosstalk among Jak-STAT, Toll-like receptor, and ITAM-dependent pathways in macrophage activation. Journal of leukocyte biology. 2007; 82:237-243.

72. $\mathrm{Hu} \mathrm{X}$, Chakravarty SD and Ivashkiv LB. Regulation of interferon and Toll-like receptor signaling during macrophage activation by opposing feedforward and feedback inhibition mechanisms. Immunological reviews. 2008; 226:41-56.

73. $\mathrm{Hu} \mathrm{X}$ and Ivashkiv LB. Cross-regulation of signaling 
pathways by interferon-gamma: implications for immune responses and autoimmune diseases. Immunity. 2009; 31:539-550.

74. Chmielewski S, Olejnik A, Sikorski K, Pelisek J, Blaszczyk K, Aoqui C, Nowicka H, Zernecke A, Heemann U, Wesoly J, Baumann M and Bluyssen HA. STAT1-dependent signal integration between IFNgamma and TLR4 in vascular cells reflect pro-atherogenic responses in human atherosclerosis. PloS one. 2014; 9:e113318.

75. Ohmori $\mathrm{Y}$ and Hamilton TA. The interferon-stimulated response element and a kappa $\mathrm{B}$ site mediate synergistic induction of murine IP-10 gene transcription by IFNgamma and TNF-alpha. Journal of immunology. 1995; 154:5235-5244.

76. Collins T, Read MA, Neish AS, Whitley MZ, Thanos D and Maniatis T. Transcriptional regulation of endothelial cell adhesion molecules: NF-kappa B and cytokine-inducible enhancers. FASEB J. 1995; 9:899-909.

77. Pietila TE, Veckman V, Lehtonen A, Lin R, Hiscott J and Julkunen I. Multiple NF-kappaB and IFN regulatory factor family transcription factors regulate CCL19 gene expression in human monocyte-derived dendritic cells. Journal of immunology. 2007; 178:253-261.

78. Liu J and Ma X. Interferon regulatory factor 8 regulates RANTES gene transcription in cooperation with interferon regulatory factor-1, NF-kappaB, and PU. 1. The Journal of biological chemistry. 2006; 281:19188-19195.

79. Pine R. Convergence of TNFalpha and IFNgamma signalling pathways through synergistic induction of IRF-1/ ISGF-2 is mediated by a composite GAS/kappaB promoter element. Nucleic acids research. 1997; 25:4346-4354.

80. Chon SY, Hassanain HH and Gupta SL. Cooperative role of interferon regulatory factor 1 and p91 (STAT1) response elements in interferon-gamma-inducible expression of human indoleamine 2,3-dioxygenase gene. The Journal of biological chemistry. 1996; 271:17247-17252.

81. Brucet M, Marques L, Sebastian C, Lloberas J and Celada A. Regulation of murine Tap1 and Lmp2 genes in macrophages by interferon gamma is mediated by STAT1 and IRF-1. Genes and immunity. 2004; 5:26-35.

82. Garner JM, Fan M, Yang CH, Du Z, Sims M, Davidoff AM and Pfeffer LM. Constitutive activation of signal transducer and activator of transcription 3 (STAT3) and nuclear factor kappaB signaling in glioblastoma cancer stem cells regulates the Notch pathway. The Journal of biological chemistry. 2013; 288:26167-26176.

83. Yu H, Pardoll D and Jove R. STATs in cancer inflammation and immunity: a leading role for STAT3. Nature reviews Cancer. 2009; 9:798-809.

84. Grivennikov SI and Karin M. Dangerous liaisons: STAT3 and NF-kappaB collaboration and crosstalk in cancer. Cytokine \& growth factor reviews. 2010; 21:11-19.

85. Kesanakurti D, Chetty C, Rajasekhar Maddirela D, Gujrati $\mathrm{M}$ and Rao JS. Essential role of cooperative NF-kappaB and
Stat3 recruitment to ICAM-1 intronic consensus elements in the regulation of radiation-induced invasion and migration in glioma. Oncogene. 2013; 32:5144-5155.

86. Sikorski K, Wesoly J and Bluyssen HA. Data mining of atherosclerotic plaque transcriptomes predicts STAT1dependent inflammatory signal integration in vascular disease. International journal of molecular sciences. 2014; 15:14313-14331.

87. Agrawal S, Febbraio M, Podrez E, Cathcart MK, Stark GR and Chisolm GM. Signal transducer and activator of transcription 1 is required for optimal foam cell formation and atherosclerotic lesion development. Circulation. 2007; 115:2939-2947.

88. Lim WS, Timmins JM, Seimon TA, Sadler A, Kolodgie FD, Virmani R and Tabas I. Signal transducer and activator of transcription-1 is critical for apoptosis in macrophages subjected to endoplasmic reticulum stress in vitro and in advanced atherosclerotic lesions in vivo. Circulation. 2008; 117:940-951.

89. Kirchmer MN, Franco A, Albasanz-Puig A, Murray J, Yagi M, Gao L, Dong ZM and Wijelath ES. Modulation of vascular smooth muscle cell phenotype by STAT-1 and STAT-3. Atherosclerosis. 2014; 234:169-175.

90. Torella D, Curcio A, Gasparri C, Galuppo V, De Serio D, Surace FC, Cavaliere AL, Leone A, Coppola C, Ellison GM and Indolfi C. Fludarabine prevents smooth muscle proliferation in vitro and neointimal hyperplasia in vivo through specific inhibition of STAT-1 activation. American journal of physiology Heart and circulatory physiology. 2007; 292:H2935-2943.

91. Manea A, Tanase LI, Raicu M and Simionescu M. Jak/ STAT signaling pathway regulates nox1 and nox4-based NADPH oxidase in human aortic smooth muscle cells. Arteriosclerosis, thrombosis, and vascular biology. 2010; 30:105-112.

92. Lagor WR, Fields DW, Bauer RC, Crawford A, Abt MC, Artis D, Wherry EJ and Rader DJ. Genetic manipulation of the ApoF/Stat2 locus supports an important role for type I interferon signaling in atherosclerosis. Atherosclerosis. 2014; 233:234-241.

93. Dutzmann J, Daniel JM, Bauersachs J, Hilfiker-Kleiner $\mathrm{D}$ and Sedding DG. Emerging translational approaches to target STAT3 signalling and its impact on vascular disease. Cardiovascular research. 2015; 106:365-374.

94. Zhou X, Li D, Yan W and Li W. Pravastatin prevents aortic atherosclerosis via modulation of signal transduction and activation of transcription 3 (STAT3) to attenuate interleukin-6 (IL-6) action in ApoE knockout mice. International journal of molecular sciences. 2008; 9:22532264.

95. Yang XP, Irani K, Mattagajasingh S, Dipaula A, Khanday F, Ozaki M, Fox-Talbot K, Baldwin WM, 3rd and Becker LC. Signal transducer and activator of transcription 3alpha and specificity protein 1 interact to upregulate intercellular adhesion molecule-1 in ischemic-reperfused myocardium 
and vascular endothelium. Arteriosclerosis, thrombosis, and vascular biology. 2005; 25:1395-1400.

96. Kleemann R, Verschuren L, Morrison M, Zadelaar $\mathrm{S}$, van Erk MJ, Wielinga PY and Kooistra T. Antiinflammatory, anti-proliferative and anti-atherosclerotic effects of quercetin in human in vitro and in vivo models. Atherosclerosis. 2011; 218:44-52.

97. Wessely R, Hengst L, Jaschke B, Wegener F, Richter T, Lupetti R, Paschalidis M, Schomig A, Brandl R and Neumann FJ. A central role of interferon regulatory factor-1 for the limitation of neointimal hyperplasia. Human molecular genetics. 2003; 12:177-187.

98. Jiang DS, Li L, Huang L, Gong J, Xia H, Liu X, Wan N, Wei X, Zhu X, Chen Y, Chen X, Zhang XD and Li $H$. Interferon regulatory factor 1 is required for cardiac remodeling in response to pressure overload. Hypertension. 2014; 64:77-86.

99. Caso JR, Pradillo JM, Hurtado O, Lorenzo P, Moro MA and Lizasoain I. Toll-like receptor 4 is involved in brain damage and inflammation after experimental stroke. Circulation. 2007; 115:1599-1608.

100. Zhang SM, Gao L, Zhang XF, Zhang R, Zhu LH, Wang PX, Tian S, Yang D, Chen K, Huang L, Zhang XD and Li H. Interferon regulatory factor 8 modulates phenotypic switching of smooth muscle cells by regulating the activity of myocardin. Molecular and cellular biology. 2014; 34:400-414.

101. Doring Y, Soehnlein O, Drechsler M, Shagdarsuren E, Chaudhari SM, Meiler S, Hartwig H, Hristov M, Koenen RR, Hieronymus T, Zenke M, Weber C and Zernecke A. Hematopoietic interferon regulatory factor 8-deficiency accelerates atherosclerosis in mice. Arteriosclerosis, thrombosis, and vascular biology. 2012; 32:1613-1623.

102. Leonard D, Svenungsson E, Sandling JK, Berggren O, Jonsen A, Bengtsson C, Wang C, Jensen-Urstad K, Granstam SO, Bengtsson AA, Gustafsson JT, Gunnarsson I, Rantapaa-Dahlqvist S, Nordmark G, Eloranta ML, Syvanen AC, et al. Coronary heart disease in systemic lupus erythematosus is associated with interferon regulatory factor- 8 gene variants. Circulation Cardiovascular genetics. 2013; 6:255-263.

103. Khallou-Laschet J, Varthaman A, Fornasa G, Compain C, Gaston AT, Clement M, Dussiot M, Levillain O, Graff-Dubois S, Nicoletti A and Caligiuri G. Macrophage plasticity in experimental atherosclerosis. PloS one. 2010; 5:e8852.

104. Xu H, Zhu J, Smith S, Foldi J, Zhao B, Chung AY, Outtz H, Kitajewski J, Shi C, Weber S, Saftig P, Li Y, Ozato K, Blobel CP, Ivashkiv LB and $\mathrm{Hu} \mathrm{X}$. NotchRBP-J signaling regulates the transcription factor IRF8 to promote inflammatory macrophage polarization. Nature immunology. 2012; 13:642-650.

105. Jiang DS, Wei X, Zhang XF, Liu Y, Zhang Y, Chen K, Gao L, Zhou H, Zhu XH, Liu PP, Bond Lau W, Ma X, Zou Y, Zhang XD, Fan GC and Li H. IRF8 suppresses pathological cardiac remodelling by inhibiting calcineurin signalling. Nature communications. 2014; 5:3303.

106. Miklossy G, Hilliard TS and Turkson J. Therapeutic modulators of STAT signalling for human diseases. Nature reviews Drug discovery. 2013; 12:611-629.

107. Kortylewski $\mathrm{M}$ and Nechaev S. Cancer therapy using oligonucleotide-based STAT3 inhibitors: will they deliver? Therapeutic delivery. 2014; 5:239-242.

108. Szelag M, Wesoly J and Bluyssen HA. Advances in peptidic and peptidomimetic-based approaches to inhibit STAT signaling in human diseases. Curr Protein Pept Sci. 2016; 17:135-146.

109. Turkson J and Jove R. STAT proteins: novel molecular targets for cancer drug discovery. Oncogene. 2000; 19:6613-6626.

110. Song H, Wang R, Wang S and Lin J. A low-molecularweight compound discovered through virtual database screening inhibits Stat3 function in breast cancer cells. Proceedings of the National Academy of Sciences of the United States of America. 2005; 102:4700-4705.

111. Miyoshi K, Takaishi M, Nakajima K, Ikeda M, Kanda T, Tarutani M, Iiyama T, Asao N, DiGiovanni J and Sano S. Stat 3 as a therapeutic target for the treatment of psoriasis: a clinical feasibility study with STA-21, a Stat3 inhibitor. J Invest Dermatol. 2011; 131:108-117.

112. Park JS, Kwok SK, Lim MA, Kim EK, Ryu JG, Kim SM, Oh HJ, Ju JH, Park SH, Kim HY and Cho ML. STA-21, a promising STAT-3 inhibitor that reciprocally regulates Th17 and Treg cells, inhibits osteoclastogenesis in mice and humans and alleviates autoimmune inflammation in an experimental model of rheumatoid arthritis. Arthritis Rheumatol. 2014; 66:918-929.

113. Schust J, Sperl B, Hollis A, Mayer TU and Berg T. Stattic: a small-molecule inhibitor of STAT3 activation and dimerization. Chem Biol. 2006; 13:1235-1242.

114. Johnson AW, Kinzenbaw DA, Modrick ML and Faraci FM. Small-molecule inhibitors of signal transducer and activator of transcription 3 protect against angiotensin II-induced vascular dysfunction and hypertension. Hypertension. 2013; 61:437-442.

115. Spitzner M, Roesler B, Bielfeld C, Emons G, Gaedcke J, Wolff HA, Rave-Frank M, Kramer F, Beissbarth T, Kitz J, Wienands J, Ghadimi BM, Ebner R, Ried T and Grade M. STAT3 inhibition sensitizes colorectal cancer to chemoradiotherapy in vitro and in vivo. Int J Cancer. 2014; 134:997-1007.

116. Matsuno K, Masuda Y, Uehara Y, Sato H, Muroya A, Takahashi O, Yokotagawa T, Furuya T, Okawara T, Otsuka M, Ogo N, Ashizawa T, Oshita C, Tai S, Ishii H, Akiyama Y, et al. Identification of a New Series of STAT3 Inhibitors by Virtual Screening. ACS Med Chem Lett. 2010; 1:371375.

117. Ashizawa T, Miyata H, Ishii H, Oshita C, Matsuno K, Masuda Y, Furuya T, Okawara T, Otsuka M, Ogo N, Asai 
A and Akiyama Y. Antitumor activity of a novel small molecule STAT3 inhibitor against a human lymphoma cell line with high STAT3 activation. International journal of oncology. 2011; 38:1245-1252.

118. Oh DY, Lee SH, Han SW, Kim MJ, Kim TM, Kim TY, Heo DS, Yuasa M, Yanagihara Y and Bang YJ. Phase I Study of OPB-31121, an Oral STAT3 Inhibitor, in Patients with Advanced Solid Tumors. Cancer Res Treat. 2015; 47:607615.

119. Hayakawa F, Sugimoto K, Harada Y, Hashimoto N, Ohi N, Kurahashi S and Naoe T. A novel STAT inhibitor, OPB-31121, has a significant antitumor effect on leukemia with STAT-addictive oncokinases. Blood Cancer J. 2013; 3:e166.

120. Kim MJ, Nam HJ, Kim HP, Han SW, Im SA, Kim TY, Oh DY and Bang YJ. OPB-31121, a novel small molecular inhibitor, disrupts the JAK2/STAT3 pathway and exhibits an antitumor activity in gastric cancer cells. Cancer Lett. 2013; 335:145-152.

121. Sakurai M, Nishio M, Yamamoto K, Okuda T, Kawano $\mathrm{K}$ and Ohnuki T. TMC-264, a novel inhibitor of STAT6 activation produced by Phoma sp. TC 1674. J Antibiot (Tokyo). 2003; 56:513-519.

122. Nakano T, Inoue H, Fukuyama S, Matsumoto K, Matsumura M, Tsuda M, Matsumoto T, Aizawa H and Nakanishi Y. Niflumic acid suppresses interleukin-13-induced asthma phenotypes. Am J Respir Crit Care Med. 2006; 173:12161221.

123. Muller J, Sperl B, Reindl W, Kiessling A and Berg T. Discovery of chromone-based inhibitors of the transcription factor STAT5. Chembiochem. 2008; 9:723-727.

124. Chiba Y, Todoroki M, Nishida Y, Tanabe M and Misawa M. A novel STAT6 inhibitor AS1517499 ameliorates antigen-induced bronchial hypercontractility in mice. Am J Respir Cell Mol Biol. 2009; 41:516-524.

125. Zhou XX, Gao PJ and Sun BG. Pravastatin attenuates interferon-gamma action via modulation of STAT1 to prevent aortic atherosclerosis in apolipoprotein E-knockout mice. Clin Exp Pharmacol Physiol. 2009; 36:373-379.

126. Lee BJ, Kim YJ, Cho DH, Sohn NW and Kang H. Immunomodulatory effect of water extract of cinnamon on anti-CD3-induced cytokine responses and p38, JNK, ERK1/2, and STAT4 activation. Immunopharmacol Immunotoxicol. 2011; 33:714-722.

127. Nelson EA, Walker SR, Weisberg E, Bar-Natan M, Barrett R, Gashin LB, Terrell S, Klitgaard JL, Santo L, Addorio MR, Ebert BL, Griffin JD and Frank DA. The STAT5 inhibitor pimozide decreases survival of chronic myelogenous leukemia cells resistant to kinase inhibitors. Blood. 2011; 117:3421-3429.

128. Bar-Natan M, Nelson EA, Walker SR, Kuang Y, Distel RJ and Frank DA. Dual inhibition of Jak2 and STAT5 enhances killing of myeloproliferative neoplasia cells. Leukemia. 2012; 26:1407-1410.
129. Lee HK, Seo IA, Shin YK, Park JW, Suh DJ and Park HT. Capsaicin inhibits the IL-6/STAT3 pathway by depleting intracellular gp130 pools through endoplasmic reticulum stress. Biochem Biophys Res Commun. 2009; 382:445-450.

130. Yang CL, Liu YY, Ma YG, Xue YX, Liu DG, Ren Y, Liu $\mathrm{XB}, \mathrm{Li}$ Y and Li Z. Curcumin blocks small cell lung cancer cells migration, invasion, angiogenesis, cell cycle and neoplasia through Janus kinase-STAT3 signalling pathway. PloS one. 2012; 7:e37960.

131. Shin DS, Kim HN, Shin KD, Yoon YJ, Kim SJ, Han DC and Kwon BM. Cryptotanshinone inhibits constitutive signal transducer and activator of transcription 3 function through blocking the dimerization in DU145 prostate cancer cells. Cancer research. 2009; 69:193-202.

132. Shakibaei M, Harikumar KB and Aggarwal BB. Resveratrol addiction: to die or not to die. Molecular nutrition \& food research. 2009; 53:115-128.

133. Sperl B, Seifert MH and Berg T. Natural product inhibitors of protein-protein interactions mediated by Src-family SH2 domains. Bioorg Med Chem Lett. 2009; 19:3305-3309.

134. Trecul A, Morceau F, Dicato M and Diederich M. Dietary compounds as potent inhibitors of the signal transducers and activators of transcription (STAT) 3 regulatory network. Genes \& nutrition. 2012; 7:111-125.

135. Deng J, Grande F and Neamati N. Small molecule inhibitors of Stat3 signaling pathway. Current cancer drug targets. 2007; 7:91-107.

136. Lavecchia MJ, Diez RP and Colinas PA. A combined theoretical and spectroscopic study of 4,6-di-O-acetyl-2,3dideoxy-D-erythro-hex-2-enopyranosyl sulfamide: a novel glycosyl carbonic anhydrase IX inhibitor. Carbohydr Res. 2011; 346:442-448.

137. Debnath B, Xu S and Neamati N. Small molecule inhibitors of signal transducer and activator of transcription 3 (Stat3) protein. Journal of medicinal chemistry. 2012; 55:66456668.

138. Szelag M, Czerwoniec A, Wesoly J and Bluyssen HA. Identification of STAT1 and STAT3 specific inhibitors using comparative virtual screening and docking validation. PloS one. 2015; 10:e116688.

139. Lin L, Hutzen B, Li PK, Ball S, Zuo M, DeAngelis S, Foust E, Sobo M, Friedman L, Bhasin D, Cen L, Li C and Lin J. A novel small molecule, LLL12, inhibits STAT3 phosphorylation and activities and exhibits potent growthsuppressive activity in human cancer cells. Neoplasia. 2010; 12:39-50.

140. Bill MA, Nicholas C, Mace TA, Etter JP, Li C, Schwartz EB, Fuchs JR, Young GS, Lin L, Lin J, He L, Phelps M, Li PK and Lesinski GB. Structurally modified curcumin analogs inhibit STAT3 phosphorylation and promote apoptosis of human renal cell carcinoma and melanoma cell lines. PloS one. 2012; 7:e40724.

141. Capiralla H, Vingtdeux V, Zhao H, Sankowski R, Al-Abed $\mathrm{Y}$, Davies $\mathrm{P}$ and Marambaud P. Resveratrol mitigates 
lipopolysaccharide- and Abeta-mediated microglial inflammation by inhibiting the TLR4/NF-kappaB/STAT signaling cascade. Journal of neurochemistry. 2012; 120:461-472.

142. Szelag M, Sikorski K, Czerwoniec A, Szatkowska K, Wesoly J and Bluyssen HA. In silico simulations of STAT1 and STAT3 inhibitors predict $\mathrm{SH} 2$ domain cross-binding specificity. European journal of pharmacology. 2013; 720:38-48.

143. Iwamura T, Yoneyama M, Yamaguchi K, Suhara W, Mori W, Shiota K, Okabe Y, Namiki H and Fujita T. Induction of IRF-3/-7 kinase and NF-kappaB in response to doublestranded RNA and virus infection: common and unique pathways. Genes Cells. 2001; 6:375-388.

144. Ali S and Kukolj G. Interferon regulatory factor 3-independent double-stranded RNA-induced inhibition of hepatitis C virus replicons in human embryonic kidney 293 cells. J Virol. 2005; 79:3174-3178.

145. Hartman AL, Dover JE, Towner JS and Nichol ST. Reverse genetic generation of recombinant Zaire Ebola viruses containing disrupted IRF-3 inhibitory domains results in attenuated virus growth in vitro and higher levels of IRF-3 activation without inhibiting viral transcription or replication. J Virol. 2006; 80:6430-6440.

146. Ren G, Cui K, Zhang Z and Zhao K. Division of labor between IRF1 and IRF2 in regulating different stages of transcriptional activation in cellular antiviral activities. Cell Biosci. 2015; 5:17.

147. Choo A, Palladinetti P, Holmes T, Basu S, Shen S, Lock RB, O'Brien TA, Symonds G and Dolnikov A. siRNA targeting the IRF2 transcription factor inhibits leukaemic cell growth. International journal of oncology. 2008; 33:175-183.

148. Bi X, Hameed M, Mirani N, Pimenta EM, Anari J and Barnes BJ. Loss of interferon regulatory factor 5 (IRF5) expression in human ductal carcinoma correlates with disease stage and contributes to metastasis. Breast Cancer Res. 2011; 13:R111.

149. Morelli E, Leone E, Cantafio ME, Di Martino MT, Amodio N, Biamonte L, Gulla A, Foresta U, Pitari MR, Botta C, Rossi M, Neri A, Munshi NC, Anderson KC, Tagliaferri $\mathrm{P}$ and Tassone P. Selective targeting of IRF4 by synthetic microRNA-125b-5p mimics induces anti-multiple myeloma activity in vitro and in vivo. Leukemia. 2015; 29:21732183.

150. Liu FC, Huang HS, Huang CY, Yang R, Chang DM, Lai $\mathrm{JH}$ and Ho LJ. A benzamide-linked small molecule HS-Cf inhibits TNF-alpha-induced interferon regulatory factor-1 in porcine chondrocytes: a potential disease-modifying drug for osteoarthritis therapeutics. J Clin Immunol. 2011; 31:1131-1142.

151. Zhao W, Qi J, Wang L, Zhang M, Wang P and Gao C. LY294002 inhibits TLR3/4-mediated IFN-beta production via inhibition of IRF3 activation with a PI3K-independent mechanism. FEBS Lett. 2012; 586:705-710.
152. Zhang X, Tao Y, Troiani L and Markovic-Plese S. Simvastatin inhibits IFN regulatory factor 4 expression and Th17 cell differentiation in CD4+ T cells derived from patients with multiple sclerosis. Journal of immunology. 2011; 187:3431-3437.

153. Dang O, Navarro L and David M. Inhibition of lipopolysaccharide-induced interferon regulatory factor 3 activation and protection from septic shock by hydroxystilbenes. Shock. 2004; 21:470-475.

154. Genin P, Morin P and Civas A. Impairment of interferoninduced IRF-7 gene expression due to inhibition of ISGF3 formation by trichostatin A. J Virol. 2003; 77:7113-7119.

155. Nikodemova M, Watters JJ, Jackson SJ, Yang SK and Duncan ID. Minocycline down-regulates MHC II expression in microglia and macrophages through inhibition of IRF-1 and protein kinase C (PKC)alpha/betaII. The Journal of biological chemistry. 2007; 282:15208-15216.

156. Furui J, Uegaki K, Yamazaki T, Shirakawa M, Swindells MB, Harada H, Taniguchi T and Kyogoku Y. Solution structure of the IRF-2 DNA-binding domain: a novel subgroup of the winged helix-turn-helix family. Structure. 1998; 6:491-500.

157. Fujii Y, Shimizu T, Kusumoto M, Kyogoku Y, Taniguchi $\mathrm{T}$ and Hakoshima T. Crystal structure of an IRF-DNA complex reveals novel DNA recognition and cooperative binding to a tandem repeat of core sequences. Embo Journal. 1999; 18:5028-5041.

158. Zhang HP, Kurosaki C, Yoshida M, Hayashi F and Yokoyama S. Solution structure of the IRF domain of human interferon regulator factors 4. Protein Data Bank. 2006.

159. Escalante CR, Nistal-Villan E, Shen LY, Garcia-Sastre A and Aggarwal AK. Structure of IRF-3 bound to the PRDIII-I regulatory element of the human interferon-beta enhancer. Mol Cell. 2007; 26:703-716.

160. Sali A and Blundell TL. Comparative protein modelling by satisfaction of spatial restraints. Journal of molecular biology. 1993; 234:779-815.

161. Dominguez C, Boelens R and Bonvin AM. HADDOCK: a protein-protein docking approach based on biochemical or biophysical information. J Am Chem Soc. 2003; 125:17311737.

162. Czerwoniec A, Szelag M, Juszczak K, Wesoly J and Bluyssen H. CAVS - Novel in silico selection strategy of specific STAT inhibitory compounds. J Comp Science. 2014.

163. Harrison C, Kiladjian JJ, Al-Ali HK, Gisslinger H, Waltzman R, Stalbovskaya V, McQuitty M, Hunter DS, Levy R, Knoops L, Cervantes F, Vannucchi AM, Barbui T and Barosi G. JAK inhibition with ruxolitinib versus best available therapy for myelofibrosis. N Engl J Med. 2012; 366:787-798.

164. Papp KA, Menter A, Strober B, Langley RG, Buonanno M, Wolk R, Gupta P, Krishnaswami S, Tan H and Harness 
JA. Efficacy and safety of tofacitinib, an oral Janus kinase inhibitor, in the treatment of psoriasis: a Phase $2 b$ randomized placebo-controlled dose-ranging study. $\mathrm{Br} \mathrm{J}$ Dermatol. 2012; 167:668-677.

165. Sandborn WJ, Ghosh S, Panes J, Vranic I, Su C, Rousell S, Niezychowski W and Study AI. Tofacitinib, an oral Janus kinase inhibitor, in active ulcerative colitis. N Engl J Med. 2012; 367:616-624.

166. Lee EB, Fleischmann R, Hall S, Wilkinson B, Bradley JD, Gruben D, Koncz T, Krishnaswami S, Wallenstein GV, Zang C, Zwillich SH, van Vollenhoven RF and Investigators OS. Tofacitinib versus methotrexate in rheumatoid arthritis. N Engl J Med. 2014; 370:2377-2386.

167. Wollenhaupt J, Silverfield J, Lee EB, Curtis JR, Wood SP, Soma K, Nduaka CI, Benda B, Gruben D, Nakamura H, Komuro Y, Zwillich SH, Wang L and Riese RJ. Safety and efficacy of tofacitinib, an oral janus kinase inhibitor, for the treatment of rheumatoid arthritis in open-label, longterm extension studies. J Rheumatol. 2014; 41:837-852.

168. Horiuchi M, Cui TX, Li Z, Li JM, Nakagami H and Iwai M. Fluvastatin enhances the inhibitory effects of a selective angiotensin II type 1 receptor blocker, valsartan, on vascular neointimal formation. Circulation. 2003; 107:106-112.

169. Banes-Berceli AK, Ketsawatsomkron P, Ogbi S, Patel B, Pollock DM and Marrero MB. Angiotensin II and endothelin-1 augment the vascular complications of diabetes via JAK2 activation. American journal of physiology Heart and circulatory physiology. 2007; 293:H1291-1299.

170. Wincewicz A, Sulkowska M, Rutkowski R, Sulkowski S, Musiatowicz B, Hirnle T, Famulski W, Koda M, Sokol $\mathrm{G}$ and Szarejko P. STAT1 and STAT3 as intracellular regulators of vascular remodeling. European Journal of Internal Medicine. 2007; 18:267-271.

171. Jiao S, Zheng X, Yang X, Zhang J and Wang L. Losartan inhibits STAT1 activation and protects human glomerular mesangial cells from angiotensin II induced premature senescence. Canadian journal of physiology and pharmacology. 2012; 90:89-98.

172. Jiao S, Meng F, Zhang J, Yang X, Zheng X and Wang L. STAT1 mediates cellular senescence induced by angiotensin II and $\mathrm{H}(2) \mathrm{O}(2)$ in human glomerular mesangial cells. Molecular and cellular biochemistry. 2012; 365:9-17.

173. Tu SP, Jin H, Shi JD, Zhu LM, Suo Y, Lu G, Liu A, Wang TC and Yang CS. Curcumin induces the differentiation of myeloid-derived suppressor cells and inhibits their interaction with cancer cells and related tumor growth. Cancer prevention research. 2012; 5:205-215.

174. Dong Y, Lu B, Zhang X, Zhang J, Lai L, Li D, Wu Y, Song Y, Luo J, Pang X, Yi Z and Liu M. Cucurbitacin E, a tetracyclic triterpenes compound from Chinese medicine, inhibits tumor angiogenesis through VEGFR2-mediated Jak2-STAT3 signaling pathway. Carcinogenesis. 2010; 31:2097-2104.

175. Sun J, Blaskovich MA, Jove R, Livingston SK, Coppola D and Sebti SM. Cucurbitacin Q: a selective STAT3 activation inhibitor with potent antitumor activity. Oncogene. 2005; 24:3236-3245.

176. Fossey SL, Bear MD, Lin J, Li C, Schwartz EB, Li PK, Fuchs JR, Fenger J, Kisseberth WC and London CA. The novel curcumin analog FLLL32 decreases STAT3 DNA binding activity and expression, and induces apoptosis in osteosarcoma cell lines. BMC cancer. 2011; 11:112.

177. Onimoe GI, Liu A, Lin L, Wei CC, Schwartz EB, Bhasin D, Li C, Fuchs JR, Li PK, Houghton P, Termuhlen A, Gross T and Lin J. Small molecules, LLL12 and FLLL32, inhibit STAT3 and exhibit potent growth suppressive activity in osteosarcoma cells and tumor growth in mice. Investigational new drugs. 2012; 30:916-926.

178. Li T, Wang W, Chen H, Li T and Ye L. Evaluation of anti-leukemia effect of resveratrol by modulating STAT3 signaling. International immunopharmacology. 2010; 10:18-25.

179. Shinriki S, Jono H, Ota K, Ueda M, Kudo M, Ota T, Oike Y, Endo M, Ibusuki M, Hiraki A, Nakayama H, Yoshitake Y, Shinohara M and Ando Y. Humanized anti-interleukin-6 receptor antibody suppresses tumor angiogenesis and in vivo growth of human oral squamous cell carcinoma. Clin Cancer Res. 2009; 15:5426-5434.

180. Zgheib A, Pelletier-Bonnier E, Levros LC, Jr. and Annabi B. Selective JAK/STAT3 signalling regulates transcription of colony stimulating factor-2 and -3 in ConcanavalinA-activated mesenchymal stromal cells. Cytokine. 2013; 63:187-193.

181. Xin H, Herrmann A, Reckamp K, Zhang W, Pal S, Hedvat M, Zhang C, Liang W, Scuto A, Weng S, Morosini D, Cao ZA, Zinda M, Figlin R, Huszar D, Jove R, et al. Antiangiogenic and antimetastatic activity of JAK inhibitor AZD1480. Cancer research. 2011; 71:6601-6610.

182. Pardanani A, Tefferi A, Jamieson C, Gabrail NY, Lebedinsky C, Gao G, Liu F, Xu C, Cao H and Talpaz M. A phase 2 randomized dose-ranging study of the JAK2selective inhibitor fedratinib (SAR302503) in patients with myelofibrosis. Blood Cancer J. 2015; 5:e335.

183. Klein JD, Sano D, Sen M, Myers JN, Grandis JR and Kim S. STAT3 oligonucleotide inhibits tumor angiogenesis in preclinical models of squamous cell carcinoma. PloS one. 2014; 9:e81819.

184. Daniel JM, Dutzmann J, Bielenberg W, Widmer-Teske R, Gunduz D, Hamm CW and Sedding DG. Inhibition of STAT3 signaling prevents vascular smooth muscle cell proliferation and neointima formation. Basic Res Cardiol. 2012; 107:261.

185. Gurbuz V, Konac E, Varol N, Yilmaz A, Gurocak S, Menevse S and Sozen S. Effects of AG490 and S3I-201 on regulation of the JAK/STAT3 signaling pathway in relation to angiogenesis in TRAIL-resistant prostate cancer cells. Oncol Lett. 2014; 7:755-763.

186. Unni S, Huang Y, Hanson RM, Tobias M, Krishnan S, Li 
WW, Nielsen JE and Baker NA. Web servers and services for electrostatics calculations with APBS and PDB2PQR. Journal of computational chemistry. 2011; 32:1488-1491.

187. Jain AN. Surflex: fully automatic flexible molecular docking using a molecular similarity-based search engine. Journal of medicinal chemistry. 2003; 46:499-511.

188. Kurowski MA and Bujnicki JM. GeneSilico protein structure prediction meta-server. Nucleic acids research. 2003; 31:3305-3307.
189. Rice P, Longden I and Bleasby A. EMBOSS: the European Molecular Biology Open Software Suite. Trends Genet. 2000; 16:276-277.

190. van Dijk M and Bonvin AM. 3D-DART: a DNA structure modelling server. Nucleic acids research. 2009; 37:W235239. 